\title{
Lifting the Veil: The Benefits of Cost Transparency
}

\section{Citation}

Mohan, Bhavya, Ryan W. Buell, and Leslie K. John. "Lifting the Veil: The Benefits of Cost Transparency." Harvard Business School Working Paper, No. 15-017, September 2014. (Revised May 2015.)

\section{Permanent link}

http://nrs.harvard.edu/urn-3:HUL.InstRepos:13360007

\section{Terms of Use}

This article was downloaded from Harvard University's DASH repository, and is made available under the terms and conditions applicable to Open Access Policy Articles, as set forth at http:// nrs.harvard.edu/urn-3:HUL.InstRepos:dash.current.terms-of-use\#OAP

\section{Share Your Story}

The Harvard community has made this article openly available.

Please share how this access benefits you. Submit a story.

\section{Accessibility}


H A R VAR D

\title{
Lifting the Veil: The Benefits of Cost Transparency
}

\author{
Bhavya Mohan \\ Ryan W. Buell \\ Leslie K. John
}

\section{Working Paper}

15-017

May 29, 2015 
Lifting the Veil: The Benefits of Cost Transparency

Bhavya Mohan, Ryan W. Buell, Leslie K. John

Harvard Business School

Harvard University

Boston, MA 02163 United States 


\section{ABSTRACT}

A firm's costs are typically tightly-guarded secrets. However, across a field study and six laboratory experiments we identify when and why firms benefit from revealing unit cost information to consumers. A natural field experiment conducted with an online retailer suggests that cost transparency boosts sales. Six subsequent controlled lab experiments replicate this basic effect (Studies 2-6) and provide evidence for why it occurs: just as interpersonal disclosure of intimate information increases attraction, cost transparency by a firm increases brand attraction, in turn boosting consumer purchase interest. This relationship persists even after controlling for perceptions of price fairness and product quality (Study 3). Study 4 suggests that the beneficial effect of cost transparency holds when firms spend more on "less desirable" costs relative to "more desirable" costs. Studies 5-6 show that the effect of cost transparency weakens when high profit margins are made salient. Finally, Study 7 shows that the beneficial effect reverses (i.e. cost transparency backfires) when it is revealed that a firm's profit margins are high relative to those of its competitors.

Keywords: cost transparency; operational transparency; purchase intentions; brand attraction; customers 


\section{INTRODUCTION}

Cost transparency refers to the voluntary disclosure of the costs associated with producing a good or providing a service. It has been studied in operations and marketing within the context of supplier-firm relationships, whereby the two-way sharing of cost information between these parties facilitates collaboration on cost reduction measures (Lamming et al. 2002; Zhu 2004). In this paper, we explore cost transparency within a different context: customer-firm relationships. Although information on the costs associated with making a good is not typically shared with customers, we test whether disclosing it may, at least in some situations, confer benefits to the firm.

In the present research, we operationalize cost transparency as the practice of revealing the unit costs of production, disclosing variable costs and apportioning relevant fixed costs. Through seven studies, we provide evidence that cost transparency can increase a consumer's interest in buying from the firm. First, in a natural experiment conducted in the field with an online retailer, sales increased when the cost to produce the good (a leather wallet) was revealed: cost transparency led to an increase in daily unit sales of the wallet. Six subsequent controlled lab experiments replicate this basic effect (Studies 2-7) and provide evidence for why it occurs: just as interpersonal disclosure of intimate information increases attraction, when a firm discloses information on costs - typically tightly-guarded secrets - it increases consumers' attraction to the firm, and in turn, their probability of making a purchase (Studies 3-7).

Further experiments explore boundary conditions. Study 4 shows that the beneficial effect of cost transparency holds when firms spend more on costs perceived to be undesirable (non value-adding costs such as transportation) relative to "desirable" costs (value-adding costs 
such as raw materials). Studies 5 and 6 show that the effect of cost transparency weakens when high profit margins are made salient. Finally, Study 7 shows that the beneficial effect reverses (i.e. cost transparency reduces willingness to purchase) when it is revealed that a firm's profit margins are high relative to those of its competitors. We argue, and our results suggest, that by revealing costs on competitively-priced products, managers can improve consumer attraction to the brand, and in turn, sales.

\section{Cost, Operational, and Price Transparency}

Although there are multiple ways of operationalizing cost transparency, broadly, cost transparency refers to the disclosure of the costs associated with producing a given product or service. In its strong form, cost transparency entails divulging all costs associated with each component of producing a good, while also clearly indicating the total cost (i.e., the sum of all cost components). We refer to this strong form as "total cost transparency" (Figure 1, Panels d h). A slightly weaker form of cost transparency entails simply divulging the costs attributable to each production factor, without explicitly highlighting the total cost. We refer to this form as “disaggregated cost transparency" (Figure 1, Panels b and c). We test both forms in the experiments that follow (spoiler alert: both are effective!).

(Insert Figure 1 about here)

Operational transparency refers to a firm's disclosure of its operating processes to customers (Buell, Tsay, \& Kim, 2014). Research suggests that consumers prefer service web sites that are operationally transparent relative to those that are not (Buell \& Norton, 2011). For example, the travel site Kayak.com is beloved in part because of its operational transparency; the site discloses which airline is being searched and updates the results throughout the search process. Such 
transparency increases consumers' perception of the effort required to create the product, in turn heightening their sense of gratitude and willingness to pay (Buell \& Norton, 2011; Gershoff, Kivetz, \& Keinan, 2012; Morales, 2005). Consistent with this line of thinking, voluntary disclosure of social and environmental impacts, such as greenhouse gas emissions, can boost a firm's market share (Kalkanci, Ang, and Plambeck 2013). Similarly, information on production processes can also affect consumers' perceptions of product quality. For example, fudge tastes better when consumers are told that it was produced using an expensive (as opposed to inexpensive) machine (Chinander and Schweitzer 2003).

Like operational transparency, cost transparency can entail revealing the steps (or processes) involved in the production of a good or service. This is because delineating the costs of each production step necessitates its revelation in some form. For example, the present experiments reveal costs through infographics that include a pictorial representation of each production factor. Thus, it is possible that cost transparency can, like operational transparency, increase consumers' perceptions of product quality. However, relative to operational transparency, cost transparency is a more intimate form of disclosure: firms are generally less comfortable disclosing their costs and hence, profit margins, relative to information on their basic production processes. ${ }^{1}$ The social psychology of self-disclosure has shown that revealing intimate information increases attraction and liking (Collins and Miller 1994). To the extent that cost transparency is a form of intimate disclosure, its effects on behavior may be driven less by perceptions of firm effort or product quality (as is the case for operational transparency), and more by increasing consumers' attraction to the firm.

Price transparency refers to disclosing the beneficiaries of a product's revenues; for example, by dividing a price into gross retail proceeds, royalties, and taxes (Carter and Curry

\footnotetext{
${ }^{1}$ Exceptions certainly apply; for example, as when the production process is a source of competitive advantage.
} 
2010). Similarly, price partitioning refers to revealing the price of the component parts of a product; for example, by dividing a product's price into its base price and shipping and handling (Bertini and Wathieu 2008; Morwitz, Greenleaf, and Johnson 1998). Price transparency and price partitioning have both been found to increase purchase intentions, and to do so via a cognitive process (Morwitz et al., 1998). Specifically, by dividing a price into several subcomponents, each of which is necessarily smaller than the total price, small prices are made salient. The result is that these tactics cause consumers to perceive prices to be relatively low, in turn increasing purchase intentions.

The logic behind the effectiveness of price transparency suggests that cost transparency might decrease purchase intent. Dividing prices into sub-components decreases perceived price. Similarly therefore, this perspective would predict that breaking down the costs of production might decrease the perceived cost of making the good, thereby increasing the perceived profit margin. To the extent that consumers think that a firm is earning a large profit on each unit sold, they may perceive the price to be unfair, and in turn be less willing to buy (Kahneman, Knetsch, $\&$ Thaler, 1986). By contrast, and as detailed in the next section, we posit that cost transparency operates through an affective process by which intimate disclosure increases consumer attraction to the firm, in turn boosting purchase interest.

In sum, cost transparency is related to, yet is distinct from, the constructs of operational transparency and price transparency.

\section{Cost Transparency as Intimate Firm Disclosure}

We suggest that cost transparency is a form of intimate disclosure by a firm to the consumer, since cost breakdowns are usually confidential, proprietary knowledge. A substantial 
body of work on the social psychology of disclosure suggests that intimate disclosure heightens relationship quality (Laurenceau, Barrett, and Pietromonaco 1998). Those who disclose intimate information are generally seen as likable (Collins and Miller 1994; Wortman et al. 1976) and attractive (Collins \& Miller, 1994; Laurenceau, Barrett, \& Pietromonaco, 1998).

Self-disclosure has been studied not only in the context of interpersonal relationships, but also in the context of human-computer interactions. For one, the mere look and feel of a website has been found to affect consumers' willingness to disclose (John, Acquisti, and Loewenstein 2011). Moreover, people are more "attracted" to computers that disclose intimate information relative to those that do not. For example, Moon (2000) demonstrated that people were more interested in using a computer that had "divulged" something sensitive - that it "rarely gets to use its full potential" - relative to a computer that had merely "divulged" that when it "doesn't have any work to do, it usually just runs a screensaver program" (Moon 2000). We posit that if an inanimate object, like a computer, can engender attraction through intimate disclosure, a firm may also benefit from the same strategy.

Of course, not all disclosure leads to attraction. Intimate disclosure that is too personal does not elicit attraction. Rather, disclosure and liking appear to have a curvilinear relationship: those who disclose at medium intimacy levels are liked more than those who disclose at very high or low levels (Cozby 1972). The intimacy of disclosure is negatively correlated with valence; the more unsavory the information, the more intimate the disclosure is typically perceived to be (Sedikides, Campbell, Reader, \& Elliot, 1999). Thus, we predict that the effectiveness of cost transparency in bolstering purchase intentions will be dampened when the firm discloses unsavory, and hence, highly intimate information, which we operationalize as high prices relative to costs, or alternatively, low costs relative to price (Studies 5, 6, and 7). 
When might cost transparency backfire? Although consumers understand and accept that firms must make profits (Bolton, Warlop, \& Alba, 2003; Kahneman et al., 1986), they punish firms that violate established norms of price fairness (Campbell 1999; Xia, Monroe, and Cox 2004). For example, most consumers react extremely negatively to a firm that dramatically increases the price, and hence, profit margins of snow shovels during a winter storm (Kahneman, Knetsch, and Thaler 1986). Therefore, we predict that consumers' purchase interest will decrease when a firm explicitly discloses that its profit margins are very high relative to market norms (i.e., relative to those of its competitors; Study 7).

\section{Overview of Studies}

Across seven studies, we test the effect of cost transparency on consumer purchase behavior. We begin by presenting the results of a natural experiment conducted in the field with an online retailer. Cost transparency led to an increase in unit sales for the target products. We subsequently present six laboratory experiments in which participants interacted with the simulated website of a fashion retailer selling t-shirts. We find that cost transparency is more effective at boosting purchase interest than operational transparency (Study 2) and provide evidence for why this is the case (Studies 3-6). The beneficial effect of cost transparency persists even when variable costs that are strongly disliked by consumers (e.g. transportation costs) are high relative to those that consumers find more palatable (e.g. raw material costs) (Study 4). Studies 5, 6, and 7 explore further boundary conditions and suggest that the benefits of cost transparency weaken, but do not reverse, as firms increase prices relative to costs, or as firms decrease costs relative to price. Only when a firm's profit margins violate market norms do we find cost transparency to backfire (Study 7). We conclude by discussing the implications of these 
findings for managers, as well as limitations and opportunities for future research.

\section{STUDY 1: FIELD EVIDENCE}

On December 2, 2013, a privately-held online retailer launched a holiday gift shop with a single email to its mailing list, promoting a leather wallet offered in five colors (burgundy, black, grey, bone, and tan) and priced at $\$ 115.00$. At the end of January, in an effort to boost postholiday sales, the retailer decided to add a cost transparency infographic to the online product detail pages of each of the wallet's five color combinations. As the wallets differed only in color, the company intended to use the same infographic for every wallet in the line.

But what the company intended to do was not what actually happened. Serendipitously (at least for us!), the company inadvertently failed to introduce the infographic for two of the wallet colors (bone and tan). Thus the infographic was implemented for only three of the five wallet colors (burgundy, black, and grey), a mistake that was overlooked for five weeks, creating a natural experiment to test the impact of cost transparency on sales.

\section{Procedure}

Operationalization of cost transparency. The company deployed total cost transparency. Specifically, along with the aggregated cost to produce the wallet, the infographic detailed the costs in a disaggregated manner; detailing the specific costs associated with each of the materials and processes involved in the production of the wallet, as follows: leather (\$14.68), construction (\$38.56), duties (\$4.26) and transportation (\$1.00). The infographic also included some other benchmarks (which we test in Study 7): the wallet had a 1.9x markup, compared to the 6x 
markup charged by a competitor. This presentation is akin to the "total + markup + benchmark" tested in Study 7 and depicted in Figure 1, Panel H.

Empirical Approach. The inadvertent provision of cost information for some, but not all, of the wallet colors served as an exogenous shock that created sets of comparable treatment (cost transparency) and control (no cost transparency) products (i.e., wallets). This treatment provides a conservative test of cost transparency, since customers browsing multiple wallet colors may have been exposed to the infographic and (correctly) inferred that the process and costs applied across color combinations. While the benefits of the infographic likely accrued to both groups, our identification comes from the fact that every customer who browsed wallets in the treatment group was exposed to the infographic, while customers who browsed wallets in the control group may not have been.

We use a difference-in-differences approach to compare the daily sales between the treatment and control groups before versus after the infographic was introduced. By doing so, we isolate the effect of cost transparency on the daily count of wallets sold in each category. We analyze the sales performance of five color combinations over a 92-day period $(N=460)$, starting with the launch of the site on December 2, 2013 and ending on March 6, 2014. The infographic was introduced on January 28, 2014.

We estimate the following linear fixed effect specification, using a Newey West estimator for standard errors that accounts for autocorrelation and heteroskedasticity within colors with a small number of products (Newey and West 1987; Schaffer 2010). ${ }^{2}$ We do not use clustered standard errors, since clustering requires a large number of clusters - far more than the five product colors we have in our dataset - to approach the true variance of the error term.

\footnotetext{
${ }^{2}$ We note that our results are substantively similar when coefficients are measured using a fixed effects Poisson specification.
} 
Using a Newey West estimator enables us to leverage the fairly long panel of sales data we have on each product color to generate a consistent estimator that accounts for the autocorrelation and heteroskedasticity within each product. This is particularly important when analyzing sales data of this type.

$$
\operatorname{COUNT}_{c, t}=f\left(\begin{array}{l}
\alpha_{0}+\alpha_{1} \text { POST }_{t}+\alpha_{2} \text { POST }_{t} \times \text { TREATMENT }_{c}+\alpha_{3} \text { VISITS }_{c, t}+\alpha_{4} \text { VISITS }_{c, t}^{2}+ \\
\alpha_{5} \text { NOVISITS }_{c, t}+\alpha_{6} \text { NOVISITS }_{c, t-1}+\alpha_{7} \text { NOSALE }_{c, t-1}+\beta_{c}+\epsilon_{c, t}
\end{array}\right)
$$

In the specification above, $\operatorname{COUNT} T_{c, t}$ represents the count of items sold for color $c$ on day t. POST $t$ is a dummy variable denoting observations after the introduction of the infographic. While the cost transparency treatment is subsumed by the color fixed effect, $\beta_{c}, P O S T_{t} \times$ TREATMENT $T_{c}$ is a dummy variable that specifically highlights observations in the cost transparency treatment conditions after the introduction of the infographic and is the focal independent variable of our analysis. VISITS ${ }_{c, t}$ and $\operatorname{VISITS}_{c, t}^{2}$ control for daily differences in visits to the product detail pages for each wallet.

A limitation of our analysis is that we were not given data on inventory levels. While the assignment of the treatment was quasi-random as described above, given the low number of products in the treatment and control groups, a stock-out could materially influence sales. To address this concern, we introduce several additional control variables. When the product is out of stock on the company's website, a "SOLD OUT" message blacks out the product on search results pages, though the product page remains accessible. NOVISITS ${ }_{c, t}$ is a dummy variable indicating whether no visits to the product page occurred for a specific color on a given day. $N O$ $\operatorname{VISITS}_{c, t-l}$ represents whether there were no visits on the preceding day. As a final proxy for stockouts, we also introduce $\operatorname{NOSALE}_{c, t-1}$, which is a dummy variable indicating whether there were no sales of a particular product on the preceding day. 


\section{Results and Discussion}

Figure 2 depicts the average daily unit sales per color over the period of analysis; Figure 3 displays this pattern in aggregate. Units are withheld from both figures to protect confidential company data. Overall, sales declined over the period, reflecting diminished demand in the postholiday season. More importantly however, there was an interaction between time and treatment: specifically, the post-holiday sales decline was smaller in the treatment condition relative to the control condition. Cost transparency therefore helped sales by serving as a buffer against postholiday sales decline.

(Insert Table 1 about here)

Table 1, Column (1) presents our base specification, in which we model the daily number of units sold per color combination as a function of the time period and treatment classification of the product group. While the focal variable is insignificant (coefficient $=0.523 ; p=0.12$ twotailed), the difference becomes marginally significant in Column (2) after controlling for the number of visits (coefficient $=0.579 ; p<0.10$ two-tailed). In Column (3), we introduce controls for whether customers visited the product on a given day, and the results intensify (coefficient $=$ $0.660 ; p<0.05$ two-tailed). In Column (4), we introduce an additional control, noting whether there were no sales the prior day, and results remain marginally significant $($ coefficient $=0.582$; $p<0.10$ two-tailed). Finally, in Column (5), we increment the bandwidth selection in the fully specified model. While the standard errors inflate, the results remain unchanged (coefficient $=$ $0.582 ; p<0.10$ two-tailed).

Using the estimates from the fully-specified model, we calculate that the cost transparency infographic increased daily unit sales on a per-color basis by $44.0 \%$ relative to average unit sales across the period of observation. Given that sales in the control and treatment 
conditions are not completely independent, customers may substitute a purchase of one wallet color for another. Hence, the magnitude of the effects we estimate through this difference-indifferences procedure are overstated. However, even when we account for this, cost transparency increases sales in the treatment condition by at least $22.0 \%{ }^{3}$ Regardless, our estimation procedure results in valid standard errors and highlights the significance of the causal effect of cost transparency on sales. As a robustness test of the significance of the effect, we perform an additional analysis, which is described below.

\section{Robustness Check}

To account for the substitution patterns among wallets in the treatment and control categories, we create an additional set of specifications that capture the daily percentage of all wallets sold that correspond with the treatment category, $T S A L E S_{-} P C T_{t}$. Importantly, we note that the ratio of wallets sold in the treatment and control conditions was time-invariant prior to the introduction of cost transparency. To facilitate our analysis, we also create an aggregated set of control variables consistent with those described above, which reflect total visits and total visits squared in each category, TVISITS $_{t}$, TVISITS $_{t}^{2}$, CVISITS $_{t}$, and CVISITS $_{t}^{2}$, the percentage of colors in each category with no visits, TNOVISIT $_{t}$ and CNOVISIT $_{t}$, the one-day lagged percentage of colors in each category with no visits, TNOVISIT ${ }_{t-1}$, and CNOVISIT $_{t-1}$, and the oneday lagged percentage of colors in each category with no sales, TNOSALE $E_{t-1}$, and CNOSALE $E_{t-1}$. We estimate the following linear specification with robust standard errors:

\footnotetext{
${ }^{3}$ If every customer who substituted a wallet in the treatment group for a wallet in the control group arrived with strong preferences for a control color, then the actual effect size of cost transparency on sales would be $22.0 \%$.
} 


$$
\text { TSALES_PCT }_{t}=f\left(\begin{array}{l}
\gamma_{0}+\gamma_{1} \text { POST }_{t}+\gamma_{2} \text { TVISITS }_{t}+\gamma_{3} \text { TVISITS }_{t}^{2}+\gamma_{4} \text { TNOVISIT }_{t}+ \\
\gamma_{5} \text { TNOVISIT }_{t-1}+\gamma_{6} \text { TNOSALE }_{t-1}+\gamma_{7} \text { CVISITS }_{t}+\gamma_{8} \text { CVISITS }_{t}^{2}+ \\
\gamma_{9} \text { CNOVISIT }_{t}+\gamma_{10} \text { CNOVISIT }_{t-1}+\gamma_{11} \text { CNOSALE }_{t-1}+\epsilon_{t}
\end{array}\right)
$$

(Insert Table 2 about here)

The results of this supplemental analysis are shown in Table (2). In all columns, the variable of interest is the coefficient on $\mathrm{POST}_{t}$, which indicates the change in the percentage of sales coming from colors in the treatment category after the introduction of cost transparency. In Column (1) the base specification reveals that the percentage of wallets sold in the treatment category, relative to the sales of all wallets, rises $12.6 \%$ following the introduction of cost transparency $($ coefficient $=0.126 ; p<0.01$ two-tailed $)$. Columns $(2-5)$ reveal that this significant increase in sales percentage is robust to the inclusion of controls for the number of times products in the treatment and control conditions were visited during the day, the percentage of colors in each category that received no visits on the focal or preceding day, and the percentage of colors in each category that resulted in no sales on the previous day. In the fully specified model, presented in Column (5), the introduction of cost transparency corresponded with a $15.7 \%$ increase in the percentage of wallets sold in the treatment condition, relative to the sales of all wallets (coefficient $=0.157 ; p<0.01$ two-sided). These results provide converging evidence of the beneficial effects of cost transparency on sales.

\section{STUDY 2: COST VERSUS OPERATIONAL TRANSPARENCY}

In a natural experiment involving a real online retailer, Study 1 suggests that cost transparency boosts sales. In the subsequent experiments, we investigate this finding in more controlled settings. Specifically, in Study 2, we test whether cost transparency alone - in the 
absence of the favorable markup benchmarks employed in Study 1 - increases purchase intent. In Study 2 and onwards, we modeled our stimuli after several burgeoning fashion e-retailers, such as the one from the field study, which have instated cost transparency (Neilson and Mistry 2013).

Participants were shown a product (a t-shirt) and indicated their interest in buying it. Between-subjects, we varied transparency: in the control condition, participants were simply told the price of the shirt. In the operational transparency condition, participants were also informed of the steps that went into making the shirt. Finally, in the cost transparency condition, participants were informed of the price plus the cost associated with each step of creating the tshirt (i.e., disaggregated cost transparency). It is conceivable that the effect of cost transparency on purchase interest could vary by profit margin: cost transparency may be less appealing, and perhaps downright unappealing, when it reveals that profit margins are high. Therefore, orthogonal to transparency, we also varied price (holding costs constant): the t-shirt was priced at $\$ 10, \$ 15$, or $\$ 20$. The study was therefore a $3 \times 3$ between-subjects design.

\section{Method}

Design and Procedure. Participants $\left(N=272, M_{\text {age }}=31.5,62 \%\right.$ male $)$ completed this online experiment in exchange for $\$ 0.25$ on the Amazon Mechanical Turk Platform. Participants first indicated their gender. Then, they were told that they would see a simulated retail website page for a product and would be asked to indicate their purchase interest. Next, participants were randomly assigned to one of nine experimental conditions, of a 3 (Price: $\$ 10, \$ 15, \$ 20$ ) x 3 (Transparency: Control, Operational, Cost) between-subjects design. The prices were comparable to other similar t-shirts found online at the time of the experiment (Everlane 2014). 
In the control condition, participants saw a baseline interface depicting a model (same gender as participant) wearing the t-shirt, the name of the product, price, available colors and sizes, and a mechanism for selecting the desired quantity for purchase (Figure 4). Unless indicated otherwise, this basic interface served as the baseline in all experiments.

\section{(Insert Figure 4 about here)}

The experimental conditions included the control information, plus an infographic containing additional information. In the operational transparency condition, the infographic was entitled "What goes into the production of our Women's [Men's] V?" and depicted six operational steps: cotton, cutting, sewing, dyeing, finishing, and transport (Figure 1, Panel A). In the cost transparency condition, the actual unit cost of each of the six operational steps, provided by our partner retailer, was also provided, i.e., $\$ 2.75, \$ 0.35, \$ 1.35, \$ 0.50, \$ 1.25$, and $\$ 0.50$ respectively (Figure 1, Panel B). Thus in this experiment, we used disaggregated cost transparency.

Dependent Measures. Participants indicated their willingness to buy the t-shirt by responding to the item: "Given the opportunity, how likely would you be to purchase this product?" (7-point response scale; $1=$ Not at all likely to $7=$ Very likely). Participants then provided their age, highest level of education, and monthly household income. Finally, in this, and Studies 5-6, participants also answered a series of secondary questions assessing their purchase experience (see Appendix) ${ }^{4}$. All experiments concluded with demographic questions unless otherwise noted. We set the desired number of participants at the outset of each experiment and did not analyze the data until that number was reached. No data were excluded

\footnotetext{
${ }^{4}$ We note that results are substantively similar after controlling for individual items in the Appendix. Covariates seldom reduced the significance of the focal independent variables, no more than would be expected by chance. Thus, we do not describe them further.
} 
and we report all manipulations and measures.

(Insert Figure 5 about here)

Results

We conducted a 3 (Price: \$10, \$15, \$20) x 3 (Transparency: Control, Operational, Cost) analysis of variance (ANOVA) on willingness to buy (Figure 5). Not surprisingly, there was a main effect of price: willingness to buy decreased as price increased $(F(2,263)=12.29, p<$ 0.01). More importantly, there was a main effect of transparency $(F(2,263)=4.69, p=0.01)$. Specifically, willingness to buy was greater in the cost transparency condition relative to both the control condition $\left(M_{\text {control }}=3.31, S D=1.87 ; M_{\text {cost }}=4.16, S D=1.98 ; t(177)=2.95, p<0.01\right)$ and the operational transparency condition $\left(M_{\text {operational }}=3.57, S D=1.80 ; t(180)=2.10, p=0.04\right)$. Willingness to buy was not significantly different between the operational transparency and control conditions $(t(181)=0.96, p=0.34)$. However, the inclusion of this condition highlights that the effects of cost transparency are distinct from the effects of operational transparency. The interaction between transparency and price was not significant, although as can be seen in Figure 5, directionally, cost transparency became less effective as price (and hence profit margins $)$ increased $(F(4,263)=0.64, p=0.64)$. Gender, education, age, and income were all non-significant when added to the model as covariates $(p>0.26)$. Throughout the rest of our experiments all reported results remain substantively the same when controlling for demographic variables (gender, education, age, and income).

\section{STUDY 3: PROCESS EVIDENCE}

Study 2 suggests that cost transparency can increase purchase interest relative to 
providing information on operational processes (and relative to a control condition in which only the price was provided). In addition, the benefit of cost transparency appeared to weaken as price (and hence, profit margins) increased. We further explore profit margins as a possible boundary condition in Study 5 and Study 6. But first, in Study 3, we replicate the basic beneficial effect of cost transparency and provide evidence of the process underlying it. Specifically, we test whether the effect of cost transparency on willingness to buy is mediated by consumer attraction to the firm (Moon 2000), and whether this mechanism holds even when controlling for two other possible process accounts: perceptions of price fairness (Bolton, Warlop, and Alba 2003) and product quality (Morales, 2003).

As in Study 2, participants were shown a product and indicated their interest in buying it. Between-subjects, we manipulated transparency (control versus cost transparency).

\section{Method}

Design and Procedure. Participants $\left(N=400, M_{\mathrm{age}}=32.0,64 \%\right.$ male $)$ completed this online experiment in exchange for $\$ 0.40$ on the Amazon Mechanical Turk platform and were randomly assigned to one of two experimental conditions varying in transparency: no transparency (control) and cost transparency. Both conditions were the same as those used in Study 2 (Figure 4 and Figure 1, Panel B), with the t-shirt priced at $\$ 10$.

Dependent Measures. We measured willingness to buy using the same scale as Study 2. We also measured our hypothesized mediator: attraction to the firm, using a modified version of Moon's (2000) scale. Specifically, participants indicated the extent to which they agreed with each of the following four statements on a 7 point scale $(1=$ strongly disagree to $7=$ strongly agree): this website represents a brand that is likable; this website represents a kind brand; this 
website represents a helpful brand; this website represents a friendly brand. We summed participants' responses to these items to create a composite measure of brand attraction (Cronbach's $\alpha=.93)$.

We also measured perceptions of price fairness and product quality. We randomly assigned participants to answer one of these two additional measures. Price fairness was assessed with the item (Bolton, Warlop, and Alba 2003): "How fair do you think the store's price is?" (7point response scale; $1=$ Not at all fair to $7=$ Very fair. Perceived product quality was assessed with the item (Morales, 2005): "What is your perceived quality of the product?" (7-point response scale; $1=$ Very low quality to $7=$ Very high quality). The order of administration was counterbalanced with respect to the brand attraction measure. Measure order had no impact, therefore the results collapse across this factor.

\section{Results}

Willingness to buy. Relative to the control, willingness to buy was significantly greater in the cost transparency condition $\left(M_{\text {control }}=4.61, S D=1.85 ; M_{\text {cost }}=5.07, S D=1.85 ; t(398)=2.66\right.$, $p<0.01)$

Brand attraction. Relative to the control, brand attraction was significantly higher in the cost transparency condition $\left(M_{\text {control }}=4.83, S D=1.17 ; M_{\text {cost }}=5.50, S D=1.03 ; t(398)=-5.99, p\right.$ $<0.01)$.

Price fairness. Perceptions of price fairness were no different between the cost transparency condition and control $\left(M_{\text {control }}=5.73, S D=0.13 ; M_{\text {cost }}=5.64, S D=0.13 ; t(196)=\right.$ $0.49, p=0.63)$.

Perceived product quality. Relative to the control, perceived product quality was 
significantly higher in the cost transparency condition $\left(M_{\text {control }}=4.79, S D=1.30 ; M_{\text {cost }}=5.20\right.$, $S D=1.30 ; t(200)=2.28, p=0.02)$.

Mediation Analysis. We tested whether brand attraction mediated willingness to buy.

First, as reported above, participants in the cost transparency condition reported higher willingness to buy $(\beta=0.47, p<0.01)$ and brand attraction $(\beta=0.66, p<0.01)$ relative to the control condition. When brand attraction and the cost transparency condition were included in the regression model predicting willingness to buy, attraction remained significant $(\beta=0.99, p<$ $0.01)$, but the effect of cost transparency was reduced to insignificance $(\beta=-0.18, p=0.30)$. Following the procedures outlined by Zhao et al. (2010), we used a bootstrap procedure to construct bias-corrected confidence intervals for the indirect effect based on 5000 resamples. The $95 \%$ bias- corrected confidence interval excluded zero $(0.43,0.89)$, providing support for full mediation (Figure 6).

\section{(Insert Figure 6 about here)}

Moreover, as reported above, cost transparency did not affect price fairness $(\beta=-0.87, p$ $=0.68)$. When price fairness, the cost transparency condition, and brand attraction were included in the regression model predicting willingness to buy, price fairness is significant $(\beta=0.73, p<$ $0.01)$; however, as before, brand attraction remains significant $(\beta=0.82, p<0.01)$, and the effect of the cost transparency condition remains insignificant $(\beta=0.09, p=0.66)$. Thus, brand attraction mediates the effect of cost transparency on willingness to buy, even when controlling for price fairness.

When product quality, the cost transparency condition, and brand attraction were included in the regression model predicting willingness to buy, perceived product quality was significant $(\beta=0.41, p<0.01)$; however, as before, attraction remained significant $(\beta=0.67, p<$ 
$0.01)$, and the effect of the cost transparency remained insignificant $(\beta=-0.25, p=0.19)$. Thus, brand attraction mediated the effect of cost transparency on willingness to buy, even when controlling for perceptions of product quality.

\section{STUDY 4: FAVORABLE VERSUS UNFAVORABLE COST ALLOCATION}

Study 3 suggests that cost transparency increases brand attraction (and in turn, purchase interest), even when controlling for perceptions of price fairness and product quality. In the studies so far, we have shown the beneficial effects of cost transparency in contexts in which the allocation of costs revealed may have been considered favorable by consumers. For example, in Studies 2 and 3, value-adding costs, such as raw materials $(\$ 2.75)$, were high relative to costs that added less direct value to the product, such as transportation $(\$ 0.50)$. Prior research suggests that consumers deem spending on cost components that do not directly add value to the principal cause to be wasteful and superfluous (Gneezy, Keenan, and Gneezy 2014). For example, people are more willing to donate to a charity when told that their donation will be used for the direct benefit of recipients (such as the provision of drinking water), relative to when it will be used toward goods that are also necessary for the organization, but do not directly add value to the cause (such as the costs of fundraising and administration). In Study 4, we test whether the effect of cost transparency holds when the allocation of costs is perceived to be less favorable. Study 4 also provides further evidence of the process underlying the beneficial effect of cost transparency, by replicating the mediation by brand attraction analysis presented in Study 3 .

\section{Method}


Pretest. We conducted a pretest $\left(N=100, M_{\text {age }}=30.4,60 \%\right.$ male) to understand the relative (un)desirability of the allocation of costs to different steps in producing a good. Participants were presented with the control stimuli from Study 2 - a t-shirt priced at $\$ 10$ - and were told that the shirt cost $\$ 6.70$ to make. Participants were then asked to estimate the cost of each of the six steps: cotton, cutting, sewing, dyeing, finishing, and transport. The estimates for cotton spending $\left(M_{\text {cotton }}=\$ 1.68, S D=0.98\right)$ and transport spending $\left(M_{\text {transport }}=\$ 1.35, S D=\right.$ 0.73 ) were significantly different from the cost allocations from Study 2 (cotton vs. \$2.75: $t(99)$ $=10.91, p<0.01$; transport vs. $\$ 0.50: t(99)=11.64, p<0.01)$. Next, participants indicated the step on which they thought the company should increase spending, and the step on which the company should decrease spending. Participants were most likely to choose "cotton" - a cost component that directly adds value to the product - as the step on which more should be spent (42\%), and "transport" - a cost component that does not directly add value to the product - as the step on which less should be spent (52\%).

Therefore, this pre-test suggests that indeed, the cost allocation used in Studies 1-3 was relatively favorable in consumers' eyes. In Study 4, we therefore manipulated the favorability of the cost allocation to test the generalizability of the capacity for cost transparency to boost purchase intent. Specifically, we test whether the effect holds when we use a less favorable allocation of costs to the different steps in creating the good.

Design and Procedure. Participants $\left(N=456,57 \%\right.$ male $\left.^{5}\right)$ completed this online experiment in exchange for $\$ 0.25$ on the Amazon Mechanical Turk platform. Participants were randomly assigned to one of three experimental conditions varying in cost transparency: no transparency, cost transparency with a favorable cost allocation, and cost transparency with an

\footnotetext{
${ }^{5}$ Due to an error, age data were not collected for this experiment, though subjects were recruited through the same platform and using the same methodology as the other experiments, so average age is likely similar.
} 
unfavorable cost allocation (Figure 1). The no transparency (control) and favorable allocation conditions were the same as the control and cost transparency conditions from Study 2, respectively (Figure 4, and Figure 1, Panel B). In the unfavorable allocation condition, the cost associated with cotton was reduced from $\$ 2.75$ to $\$ 0.50$, while the cost associated with transport was increased from $\$ 0.50$ to $\$ 2.75$ (Figure 1, Panel C). The other costs were the same as those in the favorable allocation condition. Therefore, we shifted costs from the most favored production step (raw material procurement) to the step on which pretest participants wanted the company to spend less (transportation).

Dependent Measures. The willingness to buy and composite brand attraction (Cronbach's $\alpha=.90$ ) measures were administered as in Study 3 .

Results

Willingness to buy. A one way ANOVA revealed significant differences in willingness to buy as a function of the transparency manipulation $(F(2,453)=3.58, p=0.03)$. Relative to the control, willingness to buy was significantly higher in both the favorable cost transparency condition $\left(M_{\text {control }}=4.41, S D=1.99 ; M_{\text {favorable }}=4.90, S D=1.59 ; t(299)=2.35, p=0.02\right)$ and the unfavorable cost transparency condition $\left(M_{\text {unfavorable }}=4.86, S D=1.69 ; t(303)=2.14, p=0.03\right)$. The difference between favorable and unfavorable cost transparency was not significant $(t(304)$ $=0.19, p=0.60)$.

Brand Attraction. A one way ANOVA revealed significant differences in brand attraction as a function of the transparency manipulation $(F(2,453)=13.34, p<0.01)$. Relative to control, brand attraction was significantly higher in both the favorable cost transparency condition $\left(M_{\text {control }}=4.86, S D=1.15 ; M_{\text {favorable }}=5.49, S D=0.89 ; t(299)=3.77, p<0.01\right)$ and the 
unfavorable cost transparency condition $\left(M_{\text {unfavorable }}=5.34 ; S D=1.24 ; t(303)=3.48, p<0.01\right)$. The difference between favorable and unfavorable cost transparency was not significant $(t(304)$ $=1.24, p=0.90)$.

Mediation Analysis. We again tested whether attraction mediates willingness to buy. Since the unfavorable allocation is no less transparent than the favorable allocation, we collapse the results across this factor, creating a binary cost transparency measure. The binary cost transparency measure predicted both brand attraction $(\beta=0.55, p<0.01)$ and willingness to buy $(\beta=0.47, p<0.01)$. When brand attraction and both cost transparency conditions were included in the regression model predicting willingness to buy, the effect of attraction remained significant $(\beta=0.81, p<0.01)$, but the effect of cost transparency was reduced to insignificance $(\beta=0.02, p=0.88)$ providing support for full mediation. We again used a bootstrap procedure to construct bias-corrected confidence intervals for the indirect effect based on 5000 resamples (Zhao 2010). The 95\% bias-corrected confidence interval excluded zero $(0.64,0.70)$, suggesting a significant mediation effect (Figure 6).

\section{STUDY 5: INCREASING PROFIT MARGINS (BY INCREASING PRICE)}

Study 4 suggests that the capacity for cost transparency to boost willingness to buy persists even when costs are allocated in an undesirable way and provides further evidence that this benefit is driven by brand attraction. In Study 5, we explore how profit margins (i.e., price relative to cost) moderate the effect of cost transparency on willingness to buy. Given the curvilinear relationship between disclosure intimacy and liking (Cozby 1972), we predicted that the effect of cost transparency on willingness to buy would weaken when the firm discloses high 
profit margins -- a particularly unsavory, and hence also intimate, piece of information.

We varied whether participants received information on costs, as well as the price of the product. For those who received information on costs, the cost to create the good was held constant, hence the price manipulation served to test whether the effect of cost transparency held as profit margins increased. Relative to Study 2 (in which we also varied price), Study 5 provides a more thorough investigation of the possible moderating effect of profit margins on cost transparency because it tests 14 different price points (i.e., eleven additional price points relative to Study 2).

\section{Method}

Design and Procedure. Participants ( $N=958, M_{a g e}=31.4,61 \%$ Male) completed this online experiment in exchange for $\$ 0.25$ on the Amazon Mechanical Turk platform. They were randomly assigned to one of 28 experimental conditions of a 14 (Price level: $\$ 10, \$ 15, \$ 20, \$ 25$, $\$ 30, \$ 35, \$ 40, \$ 45, \$ 50, \$ 60, \$ 70, \$ 80, \$ 90, \$ 100)$ x 2 (Transparency: Control, Cost) betweensubjects design. With the exception of the price manipulation, the control and cost transparency conditions were the same as in Study 2 (Figure 1, Panel B). We used the online website of a popular department store to determine a relevant range of product prices for similar $100 \%$ cotton plain t-shirts (\$8-\$78) (Macy’s 2014). Thus, the price manipulation reflected the varying price points a consumer might encounter in the marketplace.

Dependent Measures. The willingness to buy and composite brand attraction (Cronbach's $\alpha=0.93$ ) measures were administered as in Studies 3 and 4. 
Willingness to buy. We conducted a 14 (Price level: $\$ 10, \$ 15, \$ 20, \$ 25, \$ 30, \$ 35, \$ 40$, $\$ 45, \$ 50, \$ 60, \$ 70, \$ 80, \$ 90, \$ 100) \times 2$ (Transparency: Control, Cost) ANOVA on willingness to buy (Figure 7). Not surprisingly, willingness to buy decreased as price increased $(F(1,954)=121.2, p<0.01)$. More interestingly, cost transparency had a positive average effect on willingness to buy across all price levels $\left(M_{\text {control }}=2.26, S D=1.65 ; M_{\text {cost }}=2.48, S D=1.79\right.$; $F(1,954)=10.80, p<0.01)$. However, these main effects were qualified by a significant interaction between price and transparency $(F(1,954)=6.05, p=0.01)$. Specifically, as can be seen in Figure 7, the benefit of cost transparency decreased - but did not reverse - as price increased.

\section{(Insert Figure 7 about here)}

We conducted a follow-up analysis in which we split the sample at the median price. For the 479 participants in the below median price conditions $(<\$ 45.00)$, there was a significant main effect of cost transparency on willingness to buy $(F(1,477)=10.73, p<0.01)$. However, for the 479 participants in the above median price conditions ( $\$ 45.00$ and above), there was no significant main effect of cost transparency $(F(1,477)=0.91, p=0.34)$. This analysis provides additional support for the notion that the benefit of cost transparency is greater when profit margins are relatively small.

Brand attraction. A 14 (Price level: $\$ 10, \$ 15, \$ 20, \$ 25, \$ 30, \$ 35, \$ 40, \$ 45, \$ 50, \$ 60$, $\$ 70, \$ 80, \$ 90, \$ 100) \times 2$ (Transparency: Control, Cost) ANOVA revealed both a significant main effect of price $(F(1,941)=74.34, p<0.01)$ and cost transparency $(F(1,941)=9.61, p<$ $0.01)$. There was also a significant interaction $(F(1,941)=5.12, p=0.02)$ such that the cost transparency was most effective at increasing brand attraction at low prices.

Mediation. Replicating Studies 3 and 4, brand attraction again mediated the effect of cost 
transparency on willingness to buy. Controlling for price, cost transparency predicted both willingness to buy $(\beta=0.24, p=0.02)$ and brand attraction $(\beta=0.20, p=0.02)$. When brand attraction and cost transparency were included in the regression model predicting willingness to buy, attraction remained significant $(\beta=0.61, p<0.01)$, but the effect of cost transparency was reduced to insignificance $(\beta=0.11, p=0.21)$. We again used a bootstrap procedure to construct bias-corrected confidence intervals of the size of the indirect effect based on 5000 resamples (Zhao, Lynch Jr., and Chen 2010). The 95\% bias-corrected confidence interval excluded zero, $(0.02,0.23)$, suggesting a significant mediation effect (Figure 6).

\section{STUDY 6: INCREASING PROFIT MARGINS (BY DECREASING COSTS)}

Study 5 suggests that profit margins are a boundary condition for the capacity of cost transparency to boost purchase intentions. Surprisingly however, the effect of cost transparency on willingness to buy was merely dampened, and not reversed, by high profit margins. One possible explanation for this result is a floor effect, wherein purchase intentions, which fall as prices increase, may become so low at high prices that the salient high profit margins revealed by cost transparency have no incremental effect on purchase intentions. In Study 6, we remove this possibility by holding price constant and manipulating profit margins by varying the unit costs of production. Study 6 also provides further evidence of the process underlying the effects of cost transparency, by replicating the mediation by brand attraction analysis presented in previous studies.

\section{Method}


Design and Procedure. Participants ( $N=261, M_{a g e}=23.5,49 \%$ male) completed this experiment as part of a series of unrelated studies conducted in a university behavioral lab, in exchange for $\$ 20.00$. Participants were randomly assigned to one of three experimental conditions varying cost relative to a constant price of $\$ 10$ : no cost transparency, low total cost transparency (\$1.00), and high total cost transparency (\$9.00) (Figure 1). The no cost transparency (control) condition was the same as the control condition from Study 5 (Figure 4). In the low total cost transparency condition, the total cost of production was $\$ 1.00$ (Figure 1, Panel D). Thus, the cost of each of the six operational steps was $\$ 0.07, \$ 0.05, \$ 0.20, \$ 0.07$, $\$ 0.19$, and $\$ 0.41$. The graphic connoted the cost for each component in creating the good, as well as the total of these costs. In the high total cost transparency condition, the total cost of production was $\$ 9.00$ (Figure 1, Panel E). Thus, the cost of each of the six operational steps was $\$ 0.67, \$ 0.47, \$ 1.81, \$ 0.67, \$ 1.68$, and $\$ 3.69$, respectively.

Dependent Measures. The willingness to buy and composite brand attraction (Cronbach's $\alpha=.90$ ) measures were administered as in Studies 3-5.

\section{Results}

Willingness to buy. A one way ANOVA revealed significant differences in willingness to buy as a function of the transparency manipulation $(F(2,258)=3.31, p=0.04)$. As expected, willingness to buy was significantly higher in the high total cost transparency condition relative to the control $\left(M_{\text {control }}=4.08, S D=1.97 ; M_{\text {high }}=4.77, S D=1.90 ; t(171)=2.34, p=0.02\right)$, and relative to the low total cost transparency condition $\left(M_{\text {low }}=4.14, S D=2.04 ; t(174)=2.14, p=\right.$ 0.03). Importantly, relative to control, willingness to buy was no different in the low total cost 
transparency condition $(t(171)=0.18, p=0.86)$. Thus the benefit of cost transparency decreased - but did not reverse - as cost decreased relative to price.

Brand Attraction. A one way ANOVA revealed significant differences in brand attraction as a function of the transparency manipulation $(F(2,258)=9.49, p<0.01)$. As expected, brand attraction was significantly higher in the high total cost transparency condition relative to the control $\left(M_{\text {control }}=4.38, S D=1.20 ; M_{\text {high }}=5.23, S D=1.26 ; t(171)=4.33, p<0.01\right)$, and relative to the low total cost transparency condition $\left(M_{l o w}=4.67, S D=1.34 ; t(174)=2.76, p<0.01\right)$. Relative to the control, willingness to buy was no different in the low total cost transparency condition $(t(171)=1.47, p=0.14)$.

Mediation Analysis. We replicated the mediation analysis, excluding the low total cost transparency condition, wherein cost transparency did not increase purchase intentions. The high total cost transparency condition predicted both brand attraction $(\beta=0.42, p<0.01)$ and willingness to buy $(\beta=0.69, p=0.02)$. When brand attraction and both cost transparency conditions were included in the regression model predicting willingness to buy, the effect of attraction remained significant $(\beta=0.75, p<0.01)$, but the effect of cost transparency was reduced to insignificance $(\beta=0.03, p=0.83)$ providing support for full mediation. We again used a bootstrap procedure to construct bias-corrected confidence intervals for the indirect effect based on 5000 resamples (Zhao 2010). The 95\% bias-corrected confidence interval excluded zero $(0.32,0.98)$, suggesting a significant mediation effect (Figure 6). 
Studies 5 and 6 provide converging evidence that profit margins serve as a boundary condition for the capacity of cost transparency to boost purchase intentions: as profit margins increase, the positive impact of cost transparency on willingness to buy is attenuated. However, regardless of the method by which profit margins were manipulated (changing prices or costs), the positive effect of cost transparency on willingness to buy was only dampened, and not reversed, under high profit margins. It is possible that simply disclosing price and costs fails to make profit margins salient. In Study 7, we test whether the effect of cost transparency on purchase intent holds when profit margins are made salient, in the form of markups (i.e., representing the price in terms of its cost multiple).

There are several ways a retailer can make its markup salient. For one, a retailer can calculate and publish its markup. A retailer can also estimate and publish its competitor's markup: comparing one's prices to those of a competitor is a common marketing practice (Grewal, Monroe, and Krishnan 1998; Kahneman, Knetsch, and Thaler 1986; Miao and Mattila 2007). We anticipate that if a firm's cost transparency reveals that its own markup is higher than that of its competitors, customers will be less likely to purchase from the firm, since charging incomparably high markups is a direct violation of established norms of price fairness (Campbell 1999; Xia, Monroe, and Cox 2004).

\section{Method}

Design and Procedure. Participants $\left(N=453, M_{a g e}=31.3,59 \%\right.$ Male) completed this online experiment in exchange for $\$ 0.25$ on the Amazon Mechanical Turk platform. Participants were randomly assigned to one of 15 experimental conditions, of a 3 (Price: $\$ 10, \$ 20, \$ 30$ ) x 5 
(Transparency: Control, Disaggregated, Total, Total + Markup, Total + Markup + Benchmark) between-subjects design. The former two conditions were identical to the conditions used in Studies 2-6 (Figure 1, Panel B). The latter three conditions progressively increased markup salience. The "Total" graphic connoted the cost for each component in creating the good, as well as the total of these costs (Figure 1, Panel F). In the "Total + Markup" condition (Figure 1, Panel G), we added the firm's markup relative to cost, noting for instance, that $\$ 30$ corresponded to a 4.5X price markup (relative to the total cost of $\$ 6.70$ ). Note that the markup conditions further emphasize the firm's profit margin, a conservative design choice (i.e., is likely to bias against finding a benefit of cost transparency). Finally, in the "Total + Markup + Benchmark" condition, we further noted that a similar shirt at a 'traditional retailer' is priced at $\$ 25$, a $3.7 \mathrm{X}$ markup over the estimated cost of production (Figure 1, Panel H). Thus, at the $\$ 10$ and $\$ 20$ price points, the firm's markup was lower, and therefore, more desirable than that of its competitor, and vice versa for the $\$ 30$ price point. As previously described, this final condition exactly parallels the design of the experimental manipulation implemented in the field by our partner company in Study 1.

Dependent Measure. We used the same willingness to buy measure used in Studies 2-6.

Results

Willingness to Buy. We conducted a 3 (Price: \$10,\$20, \$30) x 5 (Transparency: Control, Disaggregated, Total, Total + Markup, Total + Markup + Benchmark) ANOVA on willingness to buy (Figure 8). As expected, there was a significant main effect of price, $F(1,443)=61.6, p$ $<0.01$ : as price increased, willingness to buy decreased. Replicating the previous studies, there was also a marginally significant main effect of transparency, $F(4,443)=1.98, p=0.10)$. These 
main effects were qualified by a marginally significant interaction between the price and transparency manipulations $(F(4,443)=8.37, p=0.06)$.

(Insert Figure 8 about here)

To better understand the relationship between price and markup salience, we indexed each of the five transparency conditions to create a continuous measure of markup salience, coded as follows: 0 (control), 1 (disaggregated), 2 (total), 3 (total + markup), and 4 (total + markup + benchmark). As price increased, so did the negative implications of greater markup salience. We then regressed willingness to buy on the continuous measure of markup salience, price, and the 2-way interaction of markup salience. As expected, the main effect of price was significant $(\beta=-0.05, p=0.01)$; the main effect of the markup salience variable was marginally significant $(\beta=0.30, p=0.08)$; and most importantly, the interaction between markup salience and price was significant and negative $(\beta=-0.02, p=0.02)$. This pattern of results suggests that the level of markup salience moderated the relationship between price (and in turn, profit margins) and cost transparency (Figure 8).

Furthermore, willingness to buy was marginally higher in the $\$ 10$ condition when competitor markups were revealed relative to the control $\left(M_{\text {control }}=3.92, S D=1.78 ; M_{\text {total }+m+b}=\right.$ $4.86, S D=1.69 ; t(51)=1.97, p=0.05)$. However, relative to the control, willingness to buy was significantly lower in the $\$ 30$ condition when competitor markups were revealed $\left(M_{\text {control }}=3.34\right.$, $\left.S D=2.13 ; M_{\text {total }+m+b}=2.17, S D=1.72 ; t(60)=2.37, p=0.02\right)$. These results suggest that by making counter-normative markups salient, cost transparency can decrease purchase intentions. 
We demonstrated that cost transparency - revealing a firm's variable costs of production - can improve customer perceptions and firm performance. Our motivating study was a natural experiment conducted in the field with an online fashion retailer. The addition of a "cost transparency" graphic denoting the costs of producing a wallet significantly increased sales over a five-week period. Cost transparency significantly increased purchase intent relative to operational transparency (and relative to a control condition in which only price was provided; Study 2). Consistent with previous research on disclosure and attraction, the effect of cost transparency on willingness to buy is mediated by consumers' attraction to the disclosing firm (Moon 2000) (Studies 3-6). Brand attraction holds as a mediator when controlling for perceptions of price fairness and product quality (Study 3). Moreover, the capacity for cost transparency to boost willingness to buy persists when costs are allocated in an undesirable way (Study 4). We then demonstrated that profit margins are a boundary condition: the benefits of cost transparency weakened - but did not reverse - when a firm disclosed higher prices relative to cost (Studies 5-6). Finally, we demonstrated that when markups are counter-normatively high compared to competitors', cost transparency decreases purchase intentions (Study 7). This research implies that by revealing costs - typically tightly-guarded secrets - managers can potentially improve both brand attraction and sales. Relative to other marketing tactics, cost transparency might be an innovative and inexpensive way to build brand attraction and sales.

\section{Limitations}

Our experimental design presented operational transparency and cost transparency in a stylized way. The effectiveness of disclosing cost information is likely affected by the presentation of information, and the source of the information. The stimuli could be potentially 
strengthened if animation or other website design changes are used to make the manipulation more salient (Buell \& Norton, 2011). Strengthening the manipulation in this way might engender the mutually reinforcing effects of cost transparency and operational transparency. Nevertheless, we note that even a simple infographic, when accompanied by the unit costs of production, is sufficient to bring about the effects we document.

All participants were American, with costs presented in US dollars. It is possible that the evaluability of different currencies could moderate consumer choices when faced with cost transparency (Hsee 1996; Raghubir and Srivastava 2002). Customers may also make negative inferences if costs are presented in other currencies that indicate low wages and poor working conditions (Paharia, Vohs, and Deshpandé 2013).

From a practical standpoint, there are important caveats a retailer would need to consider before making the decision to reveal its costs. Firms may not want to disclose their costs if their cost structure is a competitive advantage (Porter 2008). Moreover, a firm's suppliers may not allow the firm to make the costs associated with certain components public information. Thus, there could be strategic risks or contractual barriers to disclosure.

Even if firms want and are able to disclose their costs, they might not have the knowledge to do so. Disclosing the unit costs associated with the production of a single good could be particularly difficult for retailers that are not vertically integrated. While a retailer might be transparent about certain aspects of price, such as taxes (Carter and Curry 2010), it might not be feasible or even possible to comprehensively break out the costs of goods produced by a wide range of manufacturers. Moreover, for goods and services that are dependent on high fixed costs (R\&D, overhead, constant labor costs), imputing unit costs may be complicated or even confusing to consumers. For example, imputing R\&D costs on a per unit basis in a 
pharmaceutical context may require many assumptions, as well as a campaign to educate customers about how the sales of successful pharmaceuticals subsidize the production costs of less popular products as well as the costs of early-stage trials and failures. In our research, we focus on a context where unit costs can be more readily calculated and explained. We leave further investigation of the effect of cost transparency in high fixed cost environments as an opportunity for future research.

\section{Open Questions}

Our research examines the effects of cost transparency for a single firm in a single industry. Future research could explore what would happen if consumers evaluated two or more products sold by the same firm, with varying levels of transparency. Cost transparency might also seem less intimate in competitive environments when other firms also disclose their costs. Thus, future research could further explore the competitive ramifications of cost transparency, to better understand what happens in markets when multiple players reveal their costs for similar products. There is still much to explore about the benefits and potential pitfalls of cost transparency. 
REFERENCES

Bertini, Marco and Luc Wathieu (2008), "Research Note-Attention arousal through price partitioning," Marketing Science, 27 (2), 236-46.

Bolton, Lisa E., Luk Warlop, and Joseph W. Alba (2003), “Consumer Perceptions of Price (Un) Fairness," Journal of Consumer Research, 29 (4), 474-91.

Buell, Ryan, Chia-jung Tsay, and Tami Kim (2014), “Creating Reciprocal Value Through Operational Transparency,” Working Paper No. 14-115, Harvard Business School.

Buell, Ryan W. and Michael I. Norton (2011), “The Labor Illusion : How Operational Transparency Increases Perceived Value," Management Science, 57 (9), 1564-79.

Campbell, Margaret C. (1999), "Perceptions of Price Unfairness: Antecedents and Consequences," Journal of Marketing Research, 36 (2), 187-99.

Carter, Robert E. and David J. Curry (2010), “Transparent Pricing: Theory, Tests, and Implications for Marketing Practice," Journal of the Academy of Marketing Science, 38 (6), 759 74.

Chinander, Karen R and Maurice E Schweitzer (2003), “The Input Bias: The Misuse of Input Information in Judgments of Outcomes," Organizational Behavior and Human Decision Processes, 91 (2), 243-53.

Collins, Nancy L. and Lynn C. Miller (1994), "Self-disclosure and liking: a meta-analytic review.," Psychological bulletin, 116 (3), 457-75. 
Cozby, Paul C. (1972), “Self-Disclosure, Reciprocity and Liking,” Sociometry, 35, 151-60.

Everlane (2014), “Tees and Tanks," (accessed March 4, 2014), [available at https:/www.everlane.com/collections/womens-tees].

Gershoff, Andrew D., Ran Kivetz, and Anat Keinan (2012), “Consumer Response to Versioning: How Brands' Production Methods Affect Perceptions of Unfairness," Journal of Consumer Research, 39 (2), 382-98.

Gneezy, Uri, Elizabeth A. Keenan, and Ayelet Gneezy (2014), “Avoiding Overhead Aversion in Charity," Science, 346 (6209), 632-35.

Grewal, Dhruv, Kent B. Monroe, and R. Krishnan (1998), “The Effects of Price-Comparison Advertising on Buyers' Perceptions of Acquisition Value, Transaction Value, and Behavioral Intentions," The Journal of Marketing, 62 (2), 46-59.

Hsee, Christopher K. (1996), “The Evaluability Hypothesis: An Explanation for Preference Reversals Between Joint and Separate Evaluestions of Alternatives," Organizational Behavior and Human Decision Processes, 67 (3), 247-57.

John, Leslie K., Alessandro Acquisti, and George Loewenstein (2011), “Strangers on a Plane: Context-Dependent Willingness to Divulge Sensitive Information," The Journal of Consumer Research, 37 (5), 858-73.

Kahneman, Daniel, Jack L. Knetsch, and Richard Thaler (1986), "Fairness as a Constraint on Profit Ceeking: Entitlements in the Market," The American Economic Review, 76 (4), 728-41. 
Kalkanci, Basak, Erjie Ang, and Erica Plambeck (2013), "Measurement and improvement of social and environmental performance under voluntary versus mandatory disclosure," working paper, Stanford Graduate School of Business.

Lamming, Richard C., Nigel D. Caldwell, Deborah A. Harrison, and Wendy Phillips (2002), “Transparency in Supply Relationships: Concept and Practice,” IEEE Engineering Management Review, 30, 70-76.

Laurenceau, Jean-Phillipe, Lisa F. Barrett, and Paula R. Pietromonaco (1998), "Intimacy as an interpersonal process: the importance of self-disclosure, partner disclosure, and perceived partner responsiveness in interpersonal exchanges.," Journal of Personality and Social Psychology, 74 (5), 1238-51.

Macy’s (2014), “T-shirts for Women,” (accessed December 4, 2014), [available at http://www1.macys.com/cms/slp/2/T-Shirts-for-Women].

Miao, Li and Anna S. Mattila (2007), "How and How Much To Reveal? The Effects of Price Transparency On Consumers’ Price Perceptions," Journal of Hospitality \& Tourism Research, $31(4), 530-45$.

Moon, Youngme (2000), "Intimate Exchanges : Using Computers to Elicit Self-Disclosure from Consumers," Journal of Consumer Research, 26 (4), 323-39.

Morales, Andrea C. (2005), “Giving Firms an 'E' for Effort: Consumer Responses to High Effort Firms," Journal of Consumer Research, 31 (4), 806-12. 
Morwitz, Vicki G., Eric A. Greenleaf, and Eric J. Johnson (1998), “Divide to and Prosper :

Consumers' Reactions to Partitioned Prices," Journal of Marketing Research, 35 (4), 453-63.

Neilson, Laura and Meenal Mistry (2013), "Feel-Good Fashion: The New Black," (accessed January 9, 2013), [available at

http://www.wsj.com/articles/SB10001424127887323977304579001150660068542].

Newey, Whitney K. and Kenneth D. West (1987), “A Simple, Positive Semi-definite, Heteroskedasticity and Autocorrelation Consistent Covariance Matrix," Econometrica (19861998), 55, 703 .

Paharia, Neeru, Kathleen D. Vohs, and Rohit Deshpandé (2013), “Sweatshop Labor is Wrong Unless the Shoes are Cute: Cognition can both Help and Hurt Moral Motivated Reasoning," Organizational Behavior and Human Decision Processes, 121 (1), 81-88.

Porter, Michael E. (2008), Competitive advantage: Creating and sustaining superior performance, New York, Simon and Schuster.

Raghubir, Priya and Joydeep Srivastava (2002), "Effect of Face Value on Product Valuation in Foreign Currencies," Journal of Consumer Research, 29 (3), 335-47.

Schaffer, Mark E. (2010), “xtivreg2: Stata Module to Perform Extended IV/2SLS, GMM and AC/HAC, LIML and K-Class Regression for Panel Data Models," Statalist.

Sedikides, Constantine, Keith Campbell, Glenn D. Reeder, and Andrew J. Elliot (1999), “The relationship closeness induction task," Representative Research in Social Psychology, 23, 1-4. 
Wortman, Camille B., Peter Adesman, Elliot Herman, and Richard Greenberg (1976), "Selfdisclosure: an attributional perspective.," Journal of Personality and Social Psychology, 33 (2), 184-91.

Xia, Lan, Kent B. Monroe, and Jennifer L. Cox (2004), “The Price Is Unfair! A Conceptual Framework of Price Fairness Perceptions," Journal of Marketing, 68 (4), 1-15.

Zhao, Xinshu, John G. Lynch Jr., and Qimei Chen (2010), "Reconsidering Baron and Kenny: Myths and Truths about Mediation Analysis," Journal of Consumer Research, 37 (2), 197-206.

Zhu, Kevin (2004), “Information Transparency of Business-to-Business Electronic Markets: A Game-Theoretic Analysis," Management Science, 50 (5), 670-85. 


\begin{tabular}{|c|c|c|c|c|c|}
\hline & $\begin{array}{c}(1) \\
\text { Units Sold }\end{array}$ & $\begin{array}{c}(2) \\
\text { Units Sold }\end{array}$ & $\begin{array}{c}(3) \\
\text { Units Sold }\end{array}$ & $\begin{array}{c}(4) \\
\text { Units Sold }\end{array}$ & $\begin{array}{c}(5) \\
\text { Units Sold }\end{array}$ \\
\hline Post & $\begin{array}{c}-0.945^{\star * *} \\
(0.273)\end{array}$ & $\begin{array}{c}-0.921^{* * *} \\
(0.258)\end{array}$ & $\begin{array}{c}-0.959^{* * *} \\
(0.257)\end{array}$ & $\begin{array}{c}-0.850^{\star * *} \\
(0.238)\end{array}$ & $\begin{array}{c}-0.850^{* * *} \\
(0.262)\end{array}$ \\
\hline Post $\times$ Treatment & $\begin{array}{c}0.523 \\
(0.331)\end{array}$ & $\begin{array}{l}0.579^{*} \\
(0.330)\end{array}$ & $\begin{array}{l}0.660^{* *} \\
(0.328)\end{array}$ & $\begin{array}{l}0.582^{*} \\
(0.311)\end{array}$ & $\begin{array}{l}0.582^{*} \\
(0.340)\end{array}$ \\
\hline Visits & & $\begin{array}{l}0.0591^{*} \\
(0.0312)\end{array}$ & $\begin{array}{c}0.0488 \\
(0.0316)\end{array}$ & $\begin{array}{c}0.0451 \\
(0.0302)\end{array}$ & $\begin{array}{c}0.0451 \\
(0.0312)\end{array}$ \\
\hline Visits $^{2}$ & & $\begin{array}{l}-0.0002^{*} \\
(0.0001)\end{array}$ & $\begin{array}{c}-0.0002 \\
(0.0001)\end{array}$ & $\begin{array}{c}-0.0002 \\
(0.0001)\end{array}$ & $\begin{array}{c}-0.0002 \\
(0.0001)\end{array}$ \\
\hline No visit & & & $\begin{array}{c}-0.321^{* *} \\
(0.153)\end{array}$ & $\begin{array}{c}-0.300^{* *} \\
(0.152)\end{array}$ & $\begin{array}{c}-0.300^{* *} \\
(0.153)\end{array}$ \\
\hline Lagged no visit & & & $\begin{array}{l}-0.158 \\
(0.180)\end{array}$ & $\begin{array}{l}-0.113 \\
(0.183)\end{array}$ & $\begin{array}{l}-0.113 \\
(0.187)\end{array}$ \\
\hline Lagged no sale & & & & $\begin{array}{c}-0.460^{\star * *} \\
(0.142)\end{array}$ & $\begin{array}{c}-0.460^{* * *} \\
(0.150)\end{array}$ \\
\hline Observations & 460 & 460 & 460 & 460 & 460 \\
\hline Adjusted R-squared & 0.044 & 0.050 & 0.052 & 0.067 & 0.067 \\
\hline Bandwidth selection & 2 & 2 & 2 & 2 & 3 \\
\hline
\end{tabular}

Table 1: Field Evidence (Study 1). Units Sold on a Daily Basis, by Transparency Condition. Treatment variable subsumed by Fixed Effects Estimation. Fixed Effect Coefficients withheld to protect confidential company information. ${ }^{*} p<0.10,{ }^{* *} p<0.05,{ }^{* * *} p<0.01$ Two-Tailed. Robust Newey West standard errors, accounting for autocorrelation and heteroskedasticity within colors, shown in parentheses. 


\begin{tabular}{|c|c|c|c|c|c|}
\hline & $\begin{array}{c}(1) \\
\text { Treatment } \\
\text { Sales \% } \\
\end{array}$ & $\begin{array}{c}(2) \\
\text { Treatment } \\
\text { Sales \% } \\
\end{array}$ & $\begin{array}{c}(3) \\
\text { Treatment } \\
\text { Sales \% } \\
\end{array}$ & $\begin{array}{c}(4) \\
\text { Treatment } \\
\text { Sales \% } \\
\end{array}$ & $\begin{array}{c}(5) \\
\text { Treatment } \\
\text { Sales \% } \\
\end{array}$ \\
\hline Post & $\begin{array}{c}0.126^{* * *} \\
(0.047)\end{array}$ & $\begin{array}{l}0.117^{* *} \\
(0.048)\end{array}$ & $\begin{array}{l}0.117^{* *} \\
(0.049)\end{array}$ & $\begin{array}{c}0.138^{* * *} \\
(0.051)\end{array}$ & $\begin{array}{c}0.157^{* * *} \\
(0.052)\end{array}$ \\
\hline Treatment: Visits & & $\begin{array}{c}0.002 \\
(0.007)\end{array}$ & $\begin{array}{c}0.004 \\
(0.008)\end{array}$ & $\begin{array}{c}0.004 \\
(0.008)\end{array}$ & $\begin{array}{c}0.001 \\
(0.008)\end{array}$ \\
\hline Treatment: Visits ${ }^{2}$ & & $\begin{array}{c}-0.000 \\
(0.000)\end{array}$ & $\begin{array}{l}-0.000 \\
(0.000)\end{array}$ & $\begin{array}{l}-0.000 \\
(0.000)\end{array}$ & $\begin{array}{l}-0.000 \\
(0.000)\end{array}$ \\
\hline Control: Visits & & $\begin{array}{c}-0.008^{* *} \\
(0.003)\end{array}$ & $\begin{array}{l}-0.006^{*} \\
(0.004)\end{array}$ & $\begin{array}{l}-0.005 \\
(0.004)\end{array}$ & $\begin{array}{l}-0.005 \\
(0.004)\end{array}$ \\
\hline Control: Visits ${ }^{2}$ & & $\begin{array}{c}0.000^{*} \\
(0.000)\end{array}$ & $\begin{array}{c}0.000 \\
(0.000)\end{array}$ & $\begin{array}{c}0.000 \\
(0.000)\end{array}$ & $\begin{array}{c}0.000 \\
(0.000)\end{array}$ \\
\hline Treatment: No visits \% & & & $\begin{array}{c}0.120 \\
(0.130)\end{array}$ & $\begin{array}{c}0.131 \\
(0.130)\end{array}$ & $\begin{array}{c}0.181 \\
(0.131)\end{array}$ \\
\hline Control: No visits \% & & & $\begin{array}{c}0.136 \\
(0.095)\end{array}$ & $\begin{array}{c}0.140 \\
(0.095)\end{array}$ & $\begin{array}{c}0.128 \\
(0.093)\end{array}$ \\
\hline Treatment: Lagged no visits \% & & & & $\begin{array}{l}-0.070 \\
(0.116)\end{array}$ & $\begin{array}{l}-0.021 \\
(0.116)\end{array}$ \\
\hline Control: Lagged no visits \% & & & & $\begin{array}{c}0.142 \\
(0.095)\end{array}$ & $\begin{array}{c}0.149 \\
(0.096)\end{array}$ \\
\hline Treatment: Lagged no sales \% & & & & & $\begin{array}{l}-0.169 \\
(0.105)\end{array}$ \\
\hline Control: Lagged no sales \% & & & & & $\begin{array}{l}-0.077 \\
(0.068)\end{array}$ \\
\hline Constant & $\begin{array}{c}0.662^{* * *} \\
(0.030)\end{array}$ & $\begin{array}{c}0.713^{* * *} \\
(0.058)\end{array}$ & $\begin{array}{c}0.641^{* * *} \\
(0.074)\end{array}$ & $\begin{array}{c}0.608^{* * *} \\
(0.085)\end{array}$ & $\begin{array}{c}0.681^{* * *} \\
(0.090)\end{array}$ \\
\hline Observations & 92 & 92 & 92 & 92 & 92 \\
\hline Adjusted R-squared & 0.063 & 0.114 & 0.129 & 0.134 & 0.165 \\
\hline
\end{tabular}

Table 2: Field Evidence Supplemental Analysis (Study 1). Daily Percentage of Wallet Sales Attributed to the Treatment Condition (As a Percentage of All Wallets Sold). ${ }^{*} p<0.10,{ }^{* *} p<0.05$, $* * * p<0.01$ Two-Tailed. Robust standard errors shown in parentheses. 

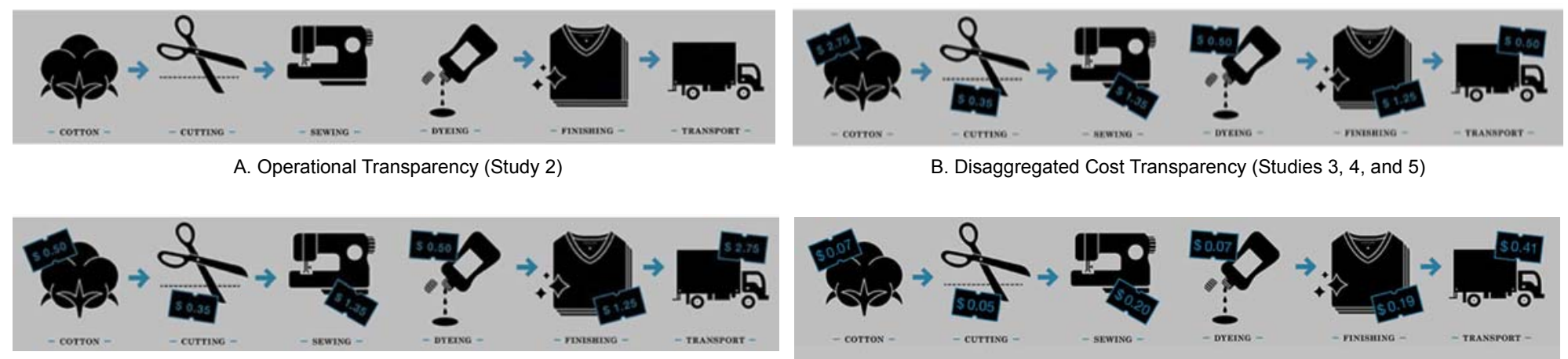

C. Unfavorable Disaggregated Cost Transparency (Study 4)

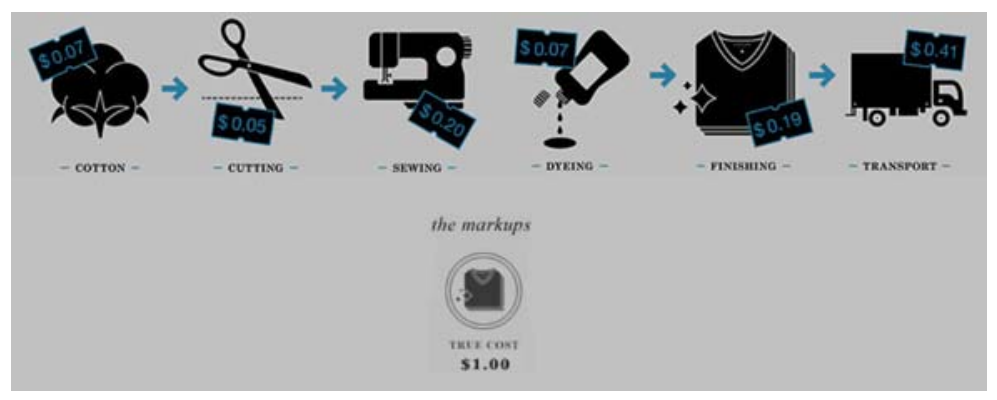

D. Low Margin Total Cost Transparency (Study 6)

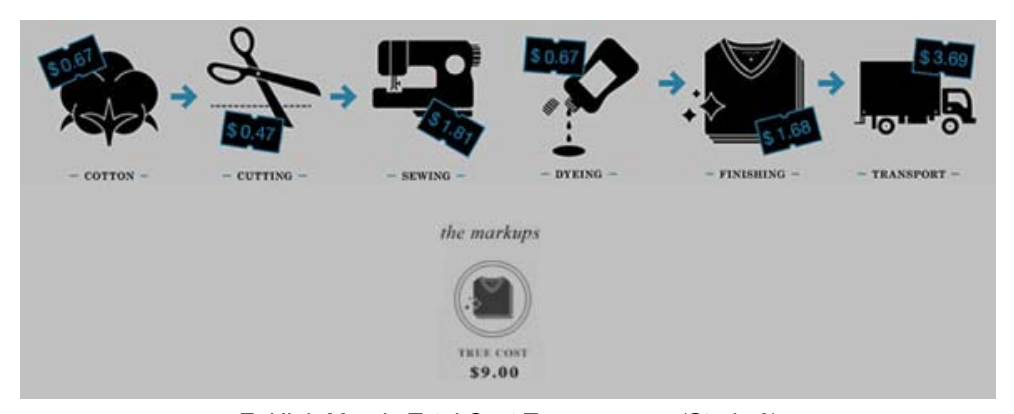

E. High Margin Total Cost Transparency (Study 6)

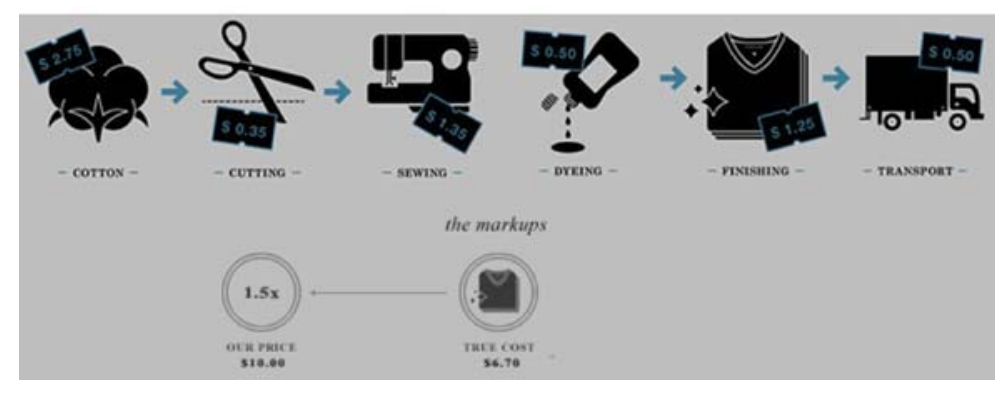

G. Total Cost Transparency + Markup (Study 7)

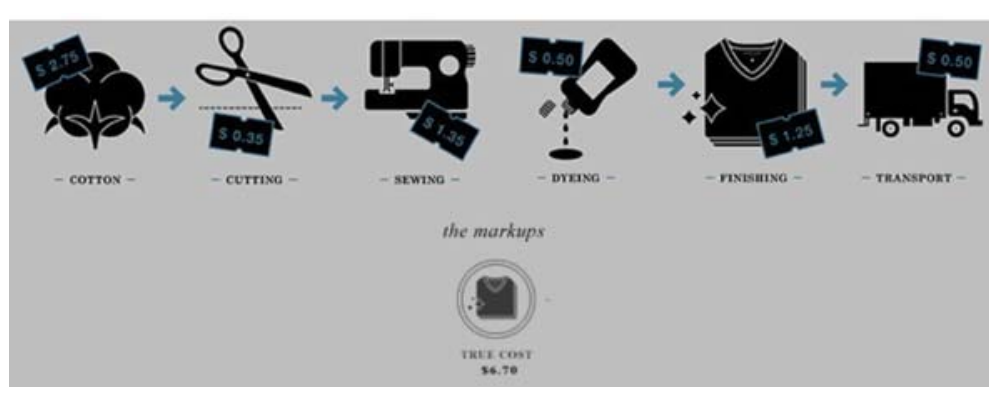

F. Total Cost Transparency (Study 7)

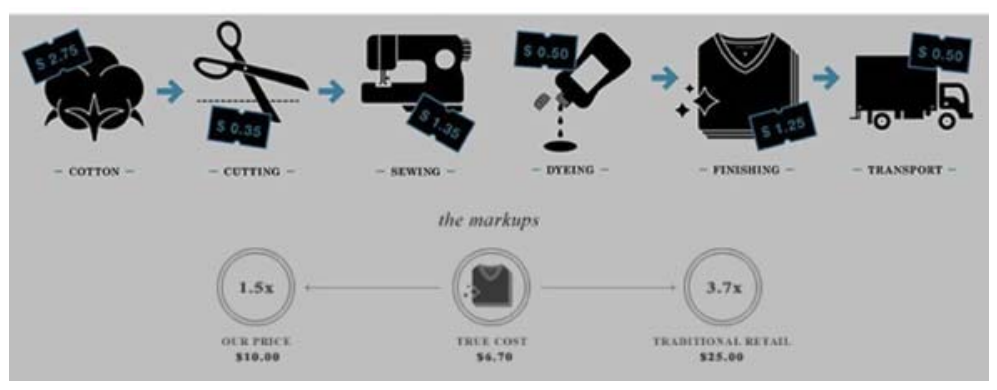

H. Total Cost Transparency + Markup + Benchmark (Study 7)

Figure 1: Operational transparency and cost transparency, as operationalized in our studies. 


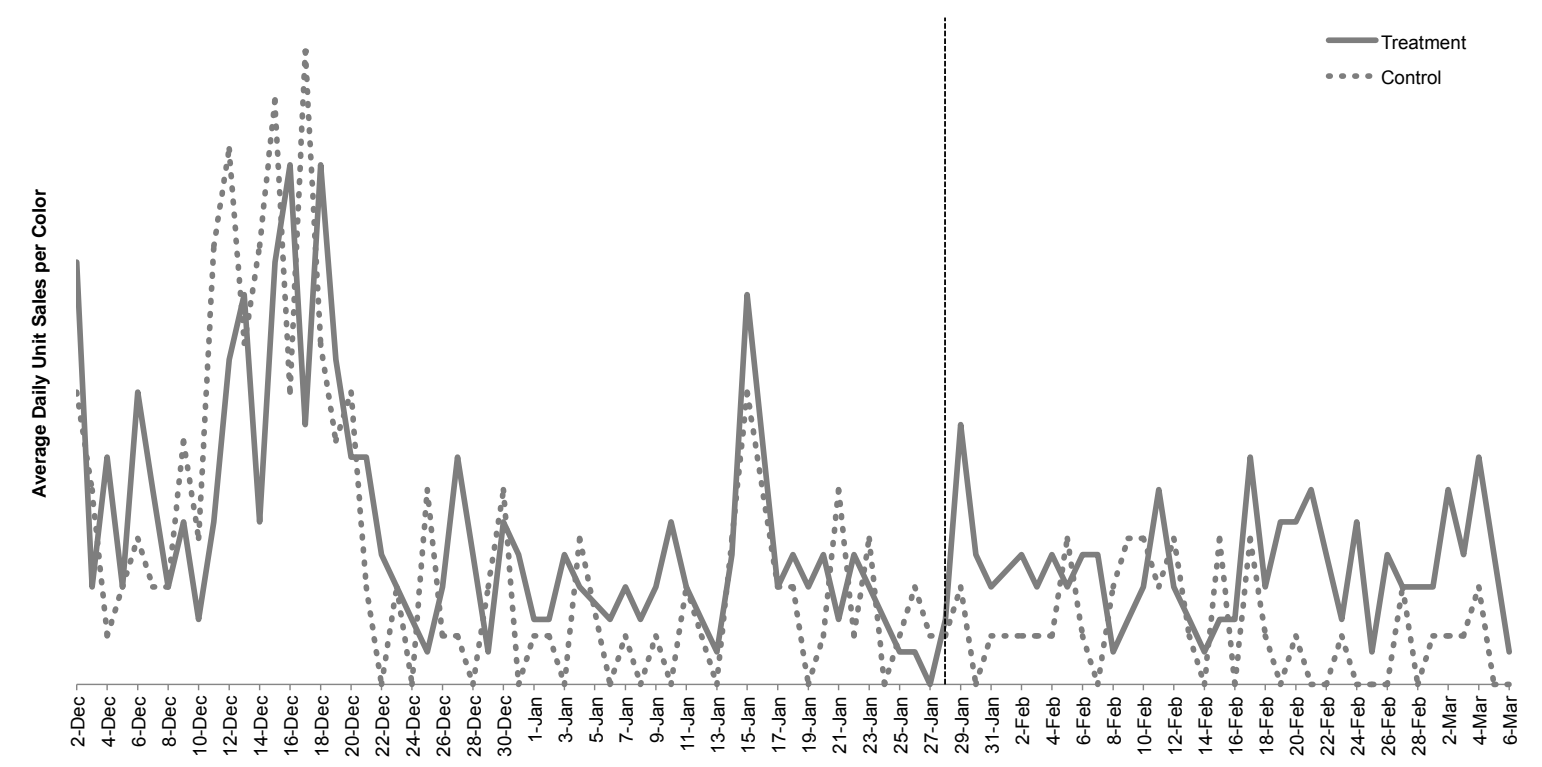

Figure 2: Field Evidence (Study 1). Average Daily Unit Sales per Treatment and Control Color. Note: Dashed vertical line indicates the date the infographic was added. Values withheld to protect confidential company information. 


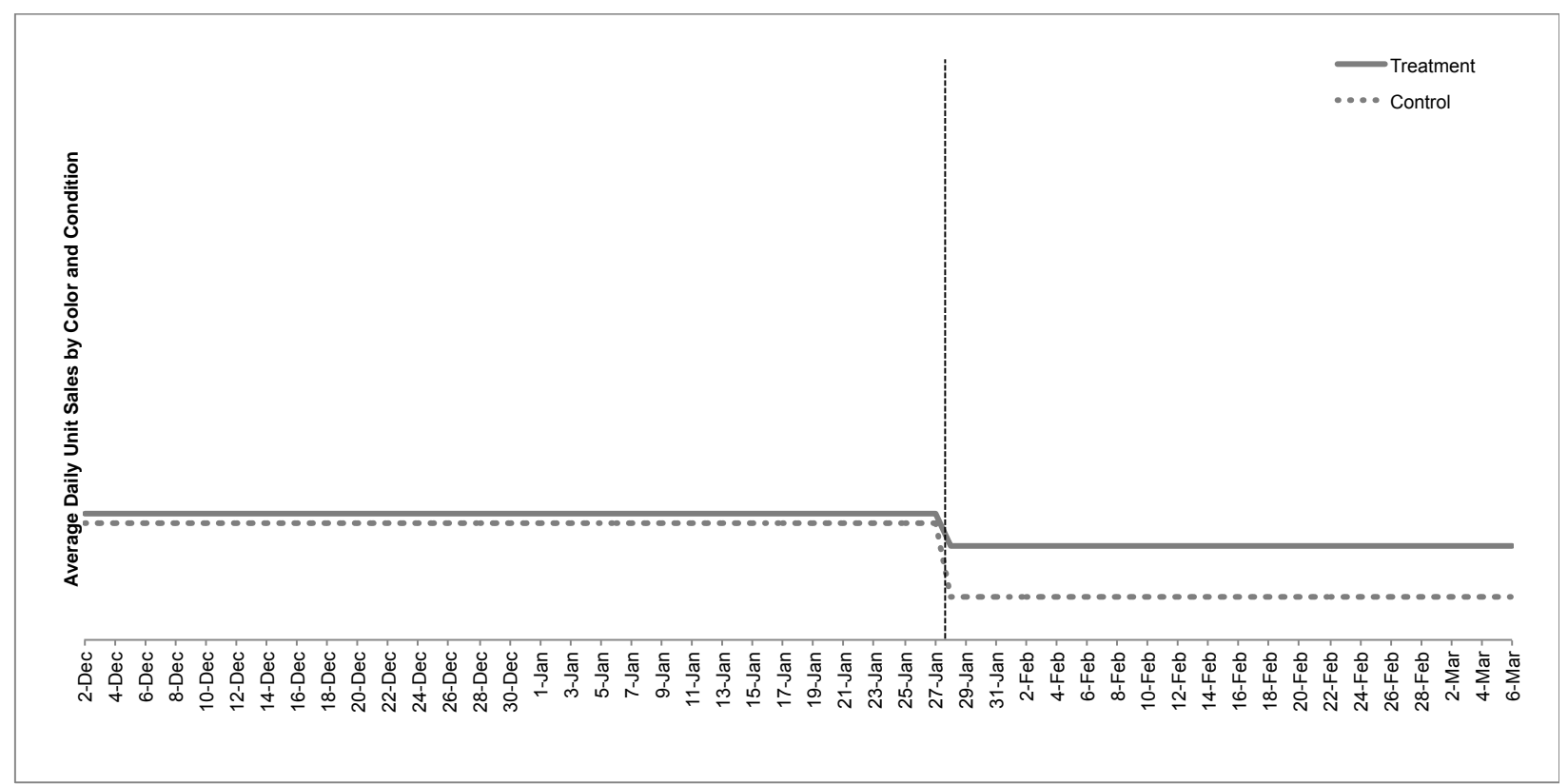

Figure 3: Field Evidence (Study 1). Average Daily Unit Sales per Treatment and Control Color Collapsed Across Pre and Post Periods.

Note: Values withheld to protect confidential company information. 

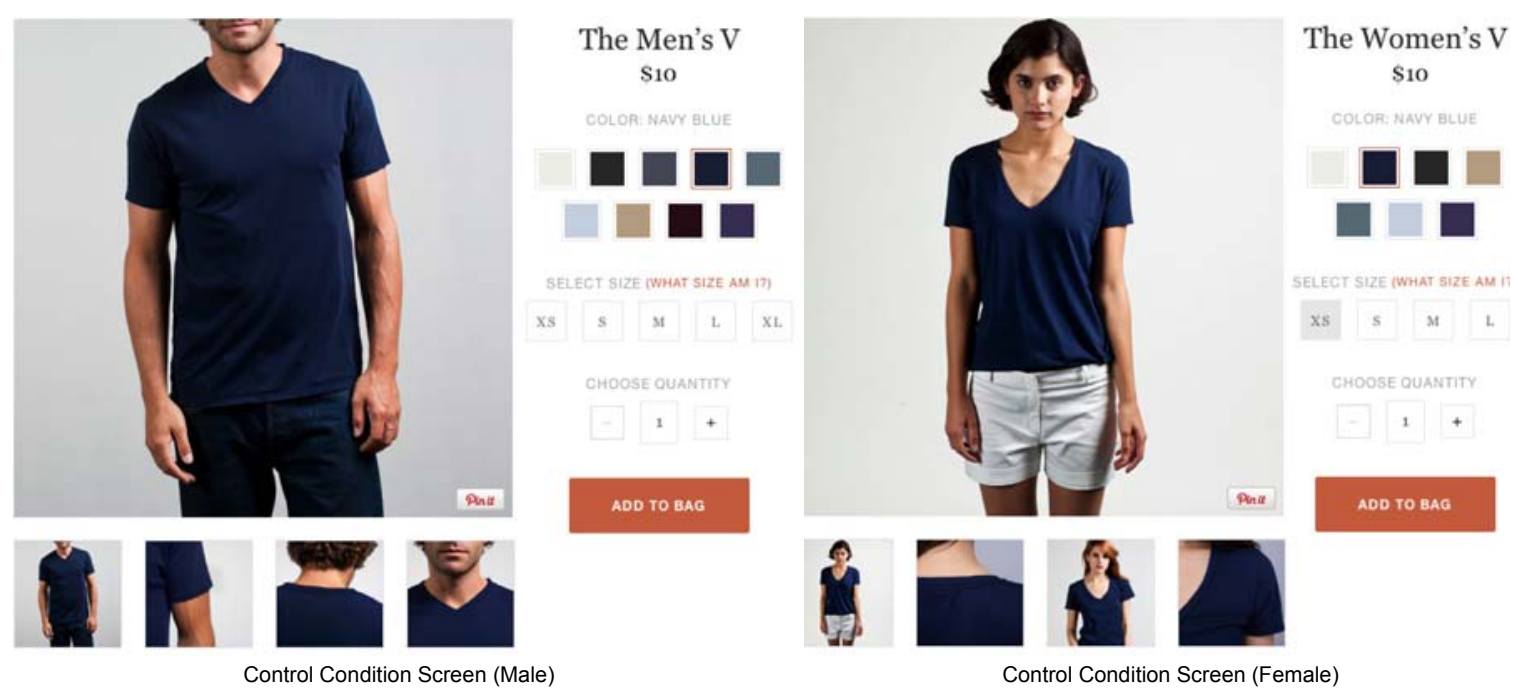

Figure 4: Control Condition Screens

Note: Screens were matched to the gender of the participant. 


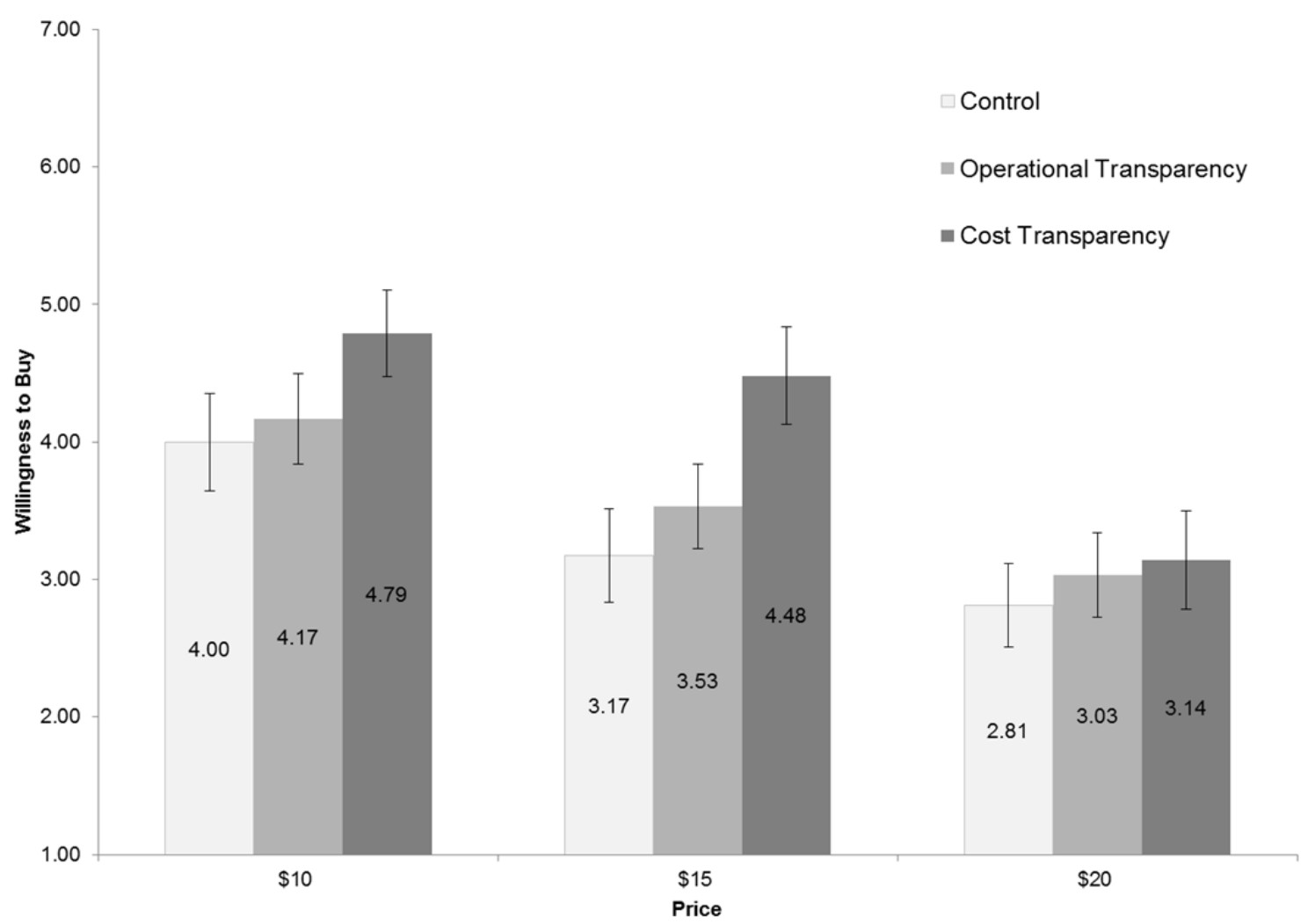

Figure 5: Study 2. Cost transparency increases willingness to buy versus control (whereas operational transparency does not). 


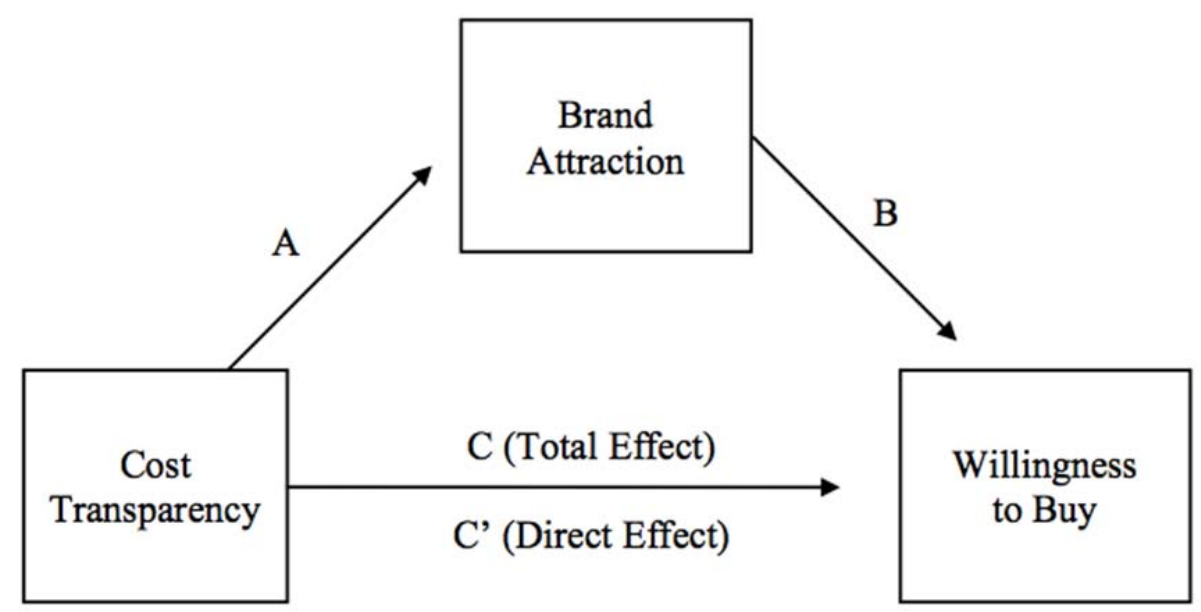

\begin{tabular}{|c|c|c|c|c|c|}
\hline Experiment & A & B & C & $\mathbf{C}^{\prime}$ & $\mathbf{C l}$ \\
\hline 3 & $\beta=0.69^{\star \star \star}$ & $\beta=0.76^{\star \star \star}$ & $\beta=0.65^{\star \star \star}$ & $\beta=0.13$ & $(0.32,0.81)$ \\
\hline 4 & $\beta=0.66^{\star \star \star}$ & $\beta=0.99^{\star \star \star}$ & $\beta=0.47^{\star \star \star}$ & $\beta=-0.18$ & $(0.43,0.89)$ \\
\hline 5 & $\beta=0.55^{\star \star \star}$ & $\beta=0.81^{\star \star \star}$ & $\beta=0.47^{\star \star \star}$ & $\beta=0.02$ & $(0.64,0.70)$ \\
\hline 6 & $\beta=0.42^{\star \star \star}$ & $\beta=0.75^{\star \star \star}$ & $\beta=0.69^{\star \star \star}$ & $\beta=0.03$ & $(0.32,0.98)$ \\
\hline
\end{tabular}

Figure 6: Studies 3, 4, 5, and 6. Brand attraction mediates the relationship between cost transparency and willingness to buy across multiple experiments. 'CI' indicates the biascorrected confidence intervals of the size of the indirect effect ( $\mathrm{a} \times \mathrm{b}$ ) based on 5000 resamples. 


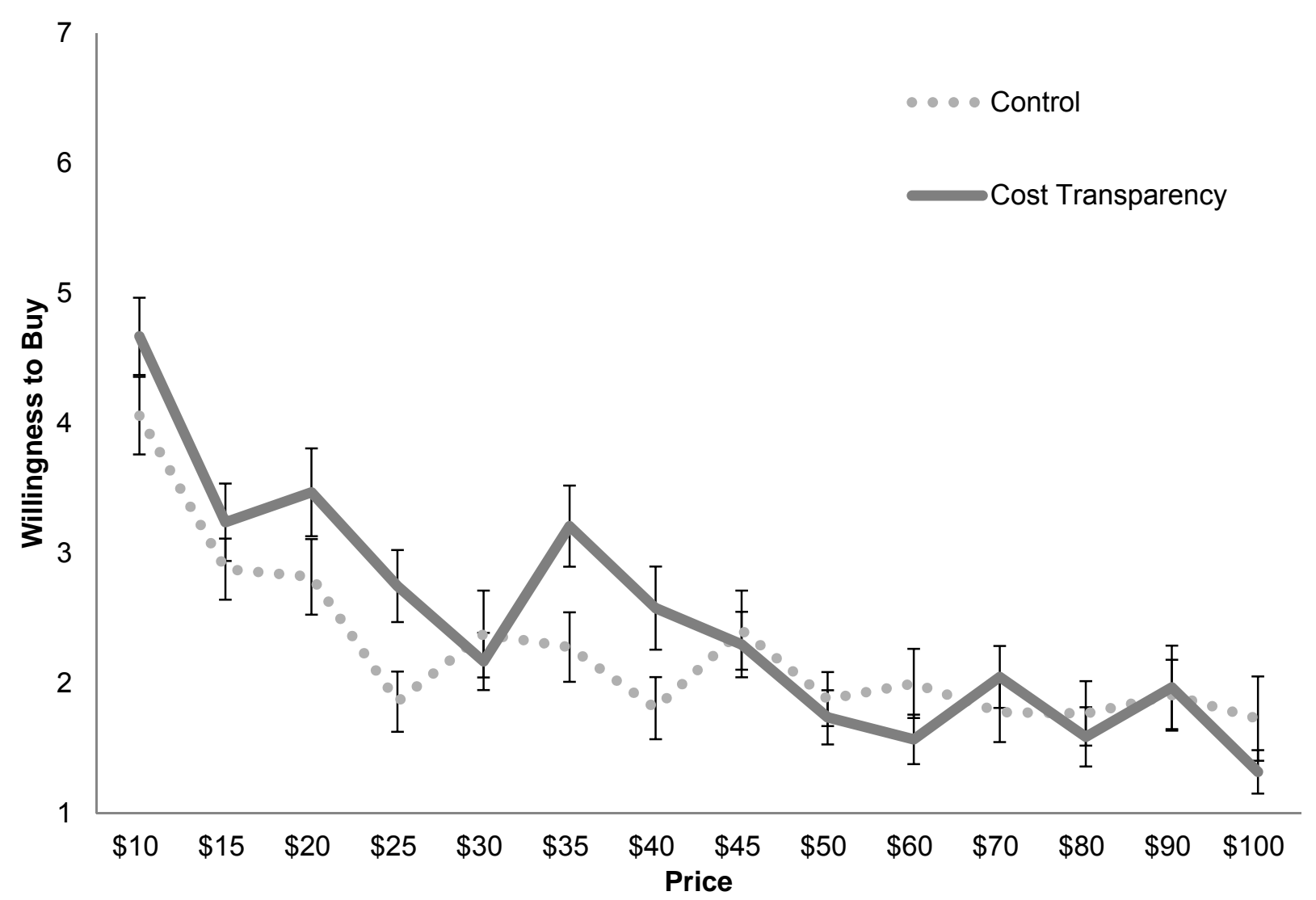

Figure 7: Study 5. The effectiveness of cost transparency decreased - but did not reverse - as price increased relative to cost. 

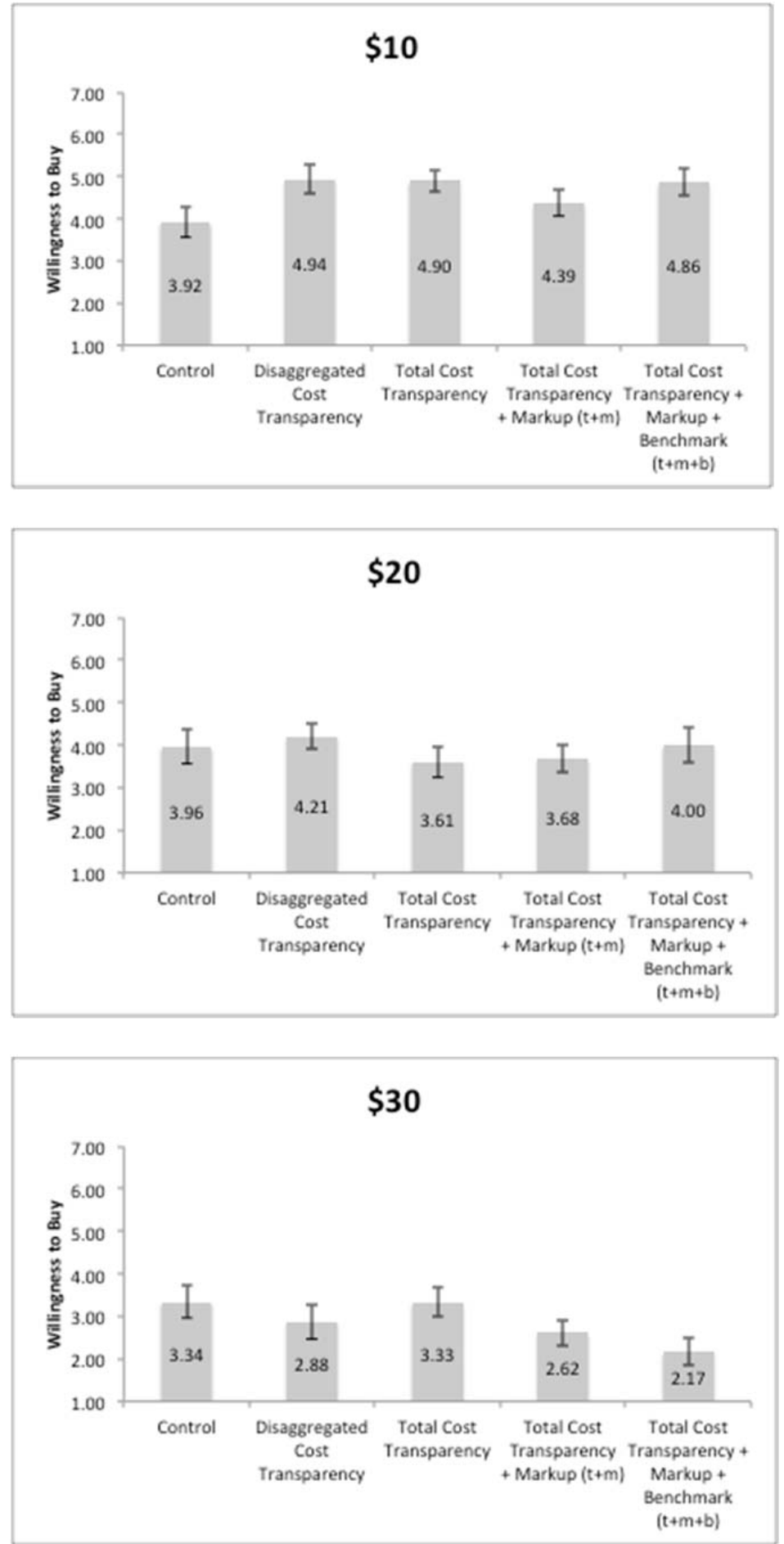

Figure 8: Study 7. Increasing markup salience diminishes the effectiveness of cost transparency, particularly at higher price points. 
Appendix

Additional Measures (Studies 2, 5, and 6)

1. How likely would you be to purchase from this website in general, either this item or another?

2. What was the price of the product you saw?

3. How much do you think it cost to make this shirt?

4. How attractive do you find this product?

5. How reasonable is the price of this product?

6. My feelings toward this retailer can best be described as: (very unsatisfied - unsatisfied).

7. If it were made available to me, over the next year, my use of this retailer would be: (very infrequent - very frequent).

8. This item is well made.

9. This item is one that would make me feel good.

10. This item is a good product for the price.

11. This item would make a good impression on other people.

12. This item is too expensive.

13. This item has consistent quality.

14. This item would not last a long time.

15. This site appears more trustworthy than other sites I've visited.

16. The site represents a company or organization that will deliver on promises made.

17. My overall trust in this product website is: (very low - very high).

18. My overall believability of the information on this site is: (very low - very high).

19. This site represents a company that engages in ethical business practices.

20. This site represents a company that pays its workers a fair wage. 